\title{
Efferent Vestibular System in the Toadfish: Action upon Horizontal Semicircular Canal Afferents
}

\author{
R. Boyle ${ }^{1,3}$ and S. M. Highstein ${ }^{2,3}$ \\ 'Departments of Otolaryngology and Physiology, Oregon Health Sciences University, Portland, Oregon 97201, \\ "Departments of Otolaryngology and Anatomy and Neurobiology, Washington University School of Medicine, St. Louis, \\ Missouri 63110, and 3 Marine Biological Laboratory, Woods Hole, Massachusetts 02543
}

\begin{abstract}
The influence of the efferent vestibular system (EVS) upon the background discharge and response dynamics of horizontal semicircular canal afferents was examined in the toadfish. In one set of experiments the EVS was activated using a behavioral paradigm; in the second, electrical shocks were applied to the efferent vestibular nucleus in the brain stem. The afferent's background discharge and responses to rotation were recorded before and during efferent stimulation. Both EVS activation paradigms gave qualitatively similar results: a facilitation of the afferent's rate, while the animal was at rest or in motion, and a reduction in response sensitivity. Afferents were not affected uniformly: low-gain, velocity-sensitive afferents were weakly influenced, while high-gain and acceleration afferents having low rates were the most excited. The afferents' phase of response was unmodified by electrical EVS stimulation. In many afferents a prominent form of response nonlinearity is discharge silencing over large portions of the stimulus cycle. Efferentevoked rate increase was often sufficient to produce a fullcycle bidirectional response. Caloric facilitation of afferent rate confirmed that the EVS-induced sensitivity decrease was rate independent. These results show a dual action of the efferent system: (1) facilitating the afferent's rate and (2) reducing its sensitivity to adequate stimulation that may be correlated with the dual EVS synaptic innervation of the labyrinth, namely postsynaptic efferent-afferent synapses and presynaptic efferent-hair cell synapses.
\end{abstract}

Efferent innervation of the auditory, vestibular, and lateral line organs has been well documented (Rasmussen and Gacek, 1958; Gacek et al., 1965; Smith and Rasmussen, 1968; Russell, 1971; Gacek and Lyon, 1974; Nakajima and Wang, 1974; Warr and Guinan, 1979; Bell, 1981; Highstein and Baker, 1986). Although there are variations in the cytoarchitecture of vestibular sensory epithelia across the vertebrate phyla, the general morphology of efferent innervation is remarkably similar. Efferent axon terminals form synaptic contacts on both the type II hair cell and afferent dendrite it supplies, and, when type I hair cells are present, on the afferent nerve chalice (Wersall, 1956; Lindeman,

Received July 13, 1989; revised Nov. 27, 1989; accepted Dec. 1, 1989.

This work was supported by NIH NS 21055, and in part from an NIH Postdoctoral Fellowship (R.B.) We wish to thank Bertha McClure for her help with the histology.

Correspondence should be addressed to Dr. R. Boyle, Department of Otolaryngology, Oregon Health Sciences University, 3515 S.W. VA Hospital Road, Portland, OR 97201.

Copyright (C) 1990 Society for Neuroscience $0270-6474 / 90 / 051570-13 \$ 02.00 / 0$
1970; Klinke and Galley, 1974; Nakajima and Wang, 1974; Sans and Highstein, 1984). There are generally many more afferents than efferents. In the toadfish, for example, there are 50 efferent axons in the horizontal canal nerve compared with 350 afferents. Further, morphological analysis of the efferent vestibular system (EVS) organization in several species reveals the presence of considerable nonspecific collateralization of labyrinthine efferents, with single efferent neurons projecting to more than one (noncoplanar) semicircular canal (Schwarz et al., 1981; Highstein and Baker, 1986). Single efferent neurons have also been reported to innervate labyrinthine and lateral line organs (Claas and Munz, 1980; Bell, 1981; Meredith and Roberts, 1986, 1987) or to bifurcate in the brain stem and innervate both labyrinths (Schwarz et al., 1981). These anatomical observations suggest that activity of the EVS may not encode information about head movement but may be related to some more general, yet undefined, function.

In the toadfish efferent vestibular neurons number 350-430 and are located bilaterally in the posterior medulla (Highstein and Baker, 1986). They are electrically coupled, presumably via electronic junctions formed by afferents that innervate multiple efferent neurons. Synaptic inputs to the EVS originate from a wide variety of sensory systems, and even vestibular sensation is represented. Sensory stimuli such as touch, vision, and sound can evoke an arousal reaction in the alert fish that is characterized by a uniform sequence of motor events. During this behavioral episode, the discharge of efferent neurons is elevated in a stereotyped fashion above the normally low rates of 4-5 to 80-100 imp/sec (Highstein and Baker, 1985). Increase in EVS activity has been causally linked to an increase in vestibular afferent activity (Highstein and Baker, 1985).

Early work on the EVS emphasized inhibition (Sala, 1965; Llinas and Precht, 1969; Flock and Russell, 1973, 1976; Klinke and Galley, 1974; Dieringer et al., 1977; Hartmann and Klinke, 1980). However, a facilitation of afferent rate by efferent stimulation is the overwhelming effect in squirrel monkey (Goldberg and Fernandez, 1980) and toadfish (Highstein and Baker, 1985) and excitation is prominent in frog (Rossi et al., 1980).

In the present experiments 2 approaches were used to activate the EVS. (1) Efferent activity was evoked behaviorally in the alert fish (Highstein and Baker, 1985) and afferents were studied before, during, and after EVS activation; this confirmed that efferent activation effects an afferent rate increase both at rest and during head movement. (2) Electrical stimulation of central efferent neurons was used to quantitate the influence on the afferent's response properties. The most prominent facilitatory action is observed on afferents having low rates that are usually 
driven to silence over portions of a sinusoidal stimulus cycle in the off-direction of rotation. EVS activation is sufficient in most cases to evoke a sustained discharge over the entire stimulus cycle, preventing the silencing of afferent firing and thus improving the bidirectionality of the response. Efferent activation can also result in gain changes to natural stimulation in some afferents. Preliminary reports of these findings have been presented (Boyle and Highstein, 1985a, b).

\section{Materials and Methods}

Results were obtained from 82 adult toadfish, Opsanus tau. Some animals also supplied data presented in the preceding study where a more complete description of the general procedures, extracellular recording, and data acquisition and analysis can be found (Boyle and Highstein, 1990). In short, the lightly anesthetized fish (Finquel, Ayerst) was perfused across the gills with sea water and secured in a tank positioned on a velocity servo-driven rate table that delivered rotational stimuli about the vertical, intercanal axis. A lateral craniotomy exposed the membraneous labyrinth, and the horizontal canal nerve was approached under visual control near the ampulla with glass microelectrodes. Unit potentials were recorded extracellularly, amplified by conventional techniques, digitized, and stored on a computer. Data analysis routines provided a quantitative description of the afferent's background discharge and the discharge modulation induced by sinusoidal rotation. An off-line computer analysis routine displayed and averaged the afferent's response to individual sinusoids in the form of cycle histograms. A computer parameter was the $D C$ fring rate, or the d-c component about which the rate oscillates, and was defined as the rate in imp/sec at half of peak-to-peak of modulation. A prominent form of nonlinearity observed in some afferents is a cessation of discharge over a part of the stimulus cycle ( $<100 \%$ conduction). If the response is assumed periodic, the $d-c$ component will drop as the silent period during a stimulus cycle lengthens, and can even take negative values when the discharge occurs for less than one-half of the rotation cycle. By definition, however, an afferent cannot have a negative firing rate. To give a nonestimated measure of an afferent's rate during rotation that is comparable between different rotational tests and among afferents, the total spikes over one cycle was measured and termed the average rate in imp/sec. The sensitivity (unnormalized gain), phase, and percent conduction (discharge time over cycle time in percent) were computed to describe the response modulation. Afferents were classified as low-gain, high-gain, or acceleration afferents; high-gain and acceleration afferents were subdivided by the coefficient of variation (CV) of their background discharge into regular $(\mathrm{R})$, intermediate $(\mathrm{M})$, or irregular (I) afferents (Boyle and Highstein, 1990).

\section{Behavioral activation}

Activation of the EVS can be evoked by lightly touching the toadfish on the snout or over the eye with a small glass probe. The succeeding behavioral response is characterized by cessation of gilling, elevation of the dorsal fin, flaring of the pectoral fins, and straightening of the body. This motor sequence usually develops over several seconds and, if fully provoked, is often followed by an attempt of the fish either to strike at the glass probe or to escape. In some experiments the onset of the behavioral response was marked by retraction of the fish's eye. Eye movement was therefore recorded. A coil of wire, consisting of 10 turns of $100-\mu \mathrm{m}$ insulated wire, was placed on the periphery of the membrane covering the cornea with cyanoacrylotate cement; a field coil was positioned about $3 \mathrm{~cm}$ away (Highstein and Baker, 1985). The resulting voltage changes in the eye coil signaled the approximate onset and termination of the behavioral reflex. During these episodes of the arousal reaction, antidromically or visually identified efferent neurons are synaptically excited and increase their firing rate (Highstein and Baker, 1985).

A series of sinusoids from $0.01-3.0 \mathrm{~Hz}(5-25 \% \mathrm{sec})$ was applied in 19 experiments to determine the afferents' response sensitivity and phase. The behavioral reflex was evoked as above to activate the EVS and the rotation cycles were repeated. During trials in which the fish attempted to either swim or attack, sustained recording from a canal afferent was usually not achievable. However, after repeated trials the fish often responds to the approach of the probe and actual tactile contact is not needed (Highstein and Baker, 1985). In these cases, the early phases of
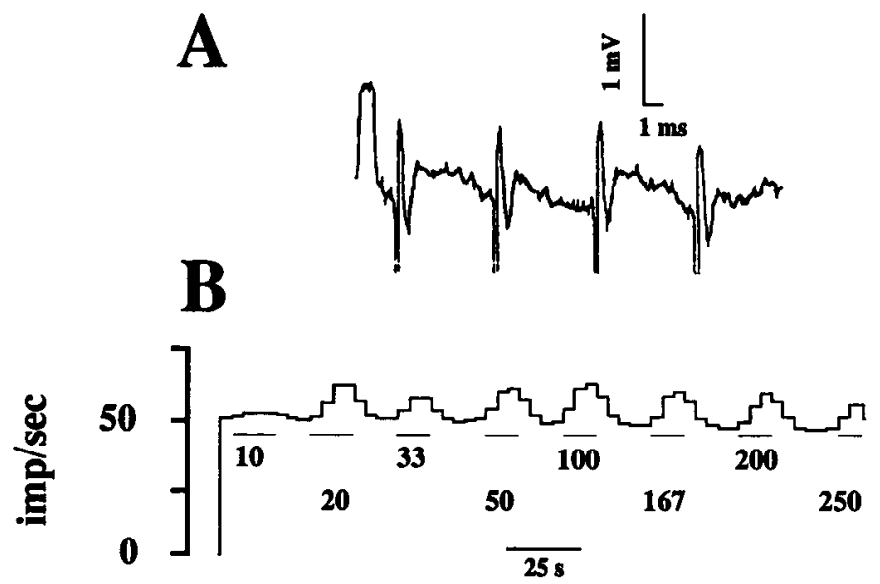

Figure 1. A, Extracellular field potentials indicate orthodromic following of efferent vestibular fibers to central stimulation of the brain stem; shock rate, 200/sec; calibration bar, $1 \mathrm{mV} / 1 \mathrm{msec}$. $B$, Histogram showing the effective range of shock rate of electrical stimulation of central efferent neurons on the discharge of a horizontal canal afferent; 100 $\mu \mathrm{sec}$ single pulses at $10-250 / \mathrm{sec}$ were applied over the period indicated by the bar beneath each rate increase.

the behavioral reflex, that is, flaring of the fins without the attempted attack or swimming movements, is evoked and, following a brief period of about $10 \mathrm{sec}$, the fish resumes a relaxed posture. Within this period unit recordings are credible. Because of the potential for contamination of the record by movement artifacts, individual tests were repeated 510 times and care was taken to substantiate the consistency and validity of the observed response. For this reason higher frequencies of rotation with shorter cycle times were preferred. Data were included in the analysis only if the rate returned to control levels following EVS activation, no injury or burst discharges occurred during the episode, and the effect was reproducible. No quantitative measure of the strength or duration of the behavioral response could be determined and therefore only a general description of the facilitatory response to behavioral activation will be given.

\section{Electrical activation of efferent neurons}

In 51 experiments the brain stem was stimulated in the region of the efferent nuclei to evaluate the influence of electrical activation of the EVS upon afferent activity (Goldberg and Fernandez, 1980). Following a midline dorsal craniotomy and cerebellar retraction, the efferent nuclei can be visualized within the floor of the IVth ventricle as paramedian gray areas between the white internal arcuate fibers (Highstein and Baker, 1986). An electrode array, consisting of 3 sharpened $\mathrm{Ag} / \mathrm{AgCl}$ wires insulated to within $0.2 \mathrm{~mm}$ of their tips and spaced $0.5 \mathrm{~mm}$ apart, was lowered into the efferent nuclei at a $45^{\circ}$ rostrocaudal angle. The orientation of the array was along the transverse axis with the center electrode on the midline. Determination of the final electrode position and the electrical current threshold needed to activate the EVS was empirically determined by observing the motor response elicited by electrical shocks of $100-\mu \mathrm{sec}$ duration applied between pairs of electrodes. The same motor sequence (arousal reaction) described above can be elicited by electrical stimulation of the efferent vestibular nuclei. Flaring of the fins is the first response triggered by low-intensity electrical stimulation, while increasing the stimulus intensity or duration evokes the remainder of the response sequentially. The magnitude of the induced behavioral sequence guided the placing of the stimulating array within the efferent nuclei: the final position of the electrodes was adjusted to the site that required the lowest shock intensity to elicit the initial stages of the response. This stimulus intensity (usually $<0.5 \mathrm{~V}$ ) was defined as threshold $(T)$ and was checked periodically throughout the recording session. The lowest $\mathrm{T}$ electrode site also proved to be the most effective for consistently evoking rate changes in afferents.

To verify electrode placement at the end of the experiment the fish was deeply anesthetized, perfused transcardially with a solution of $1 \%$ paraformaldehyde and $1 \%$ glutaraldehyde in $0.1 \mathrm{~m}$ phosphate buffer, and the brain removed. Sixty-micrometer serial sections of the brain 

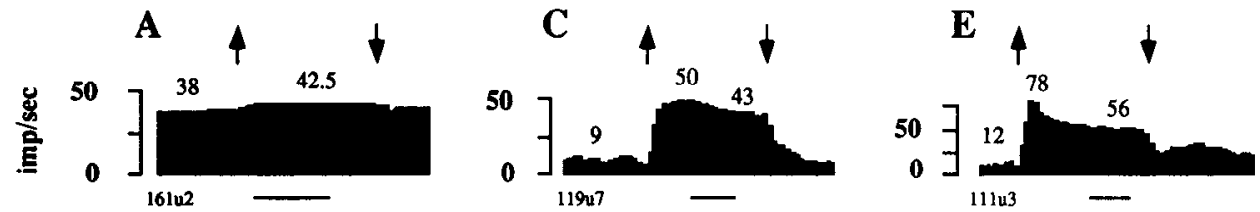

Figure 2. Facilitation of background discharge of 6 horizontal canal afferents by electrical stimulation of central efferent neurons. Downward and upward arrows indicate the beginning and end, respectively, of efferent stimulation. Horizontal bars under each histogram are $10 \mathrm{sec}$.
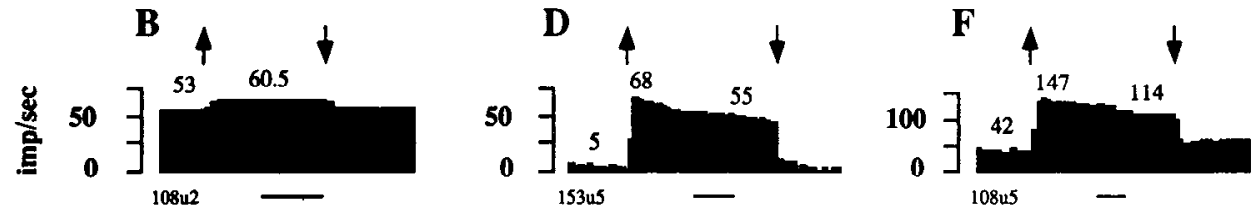

stem were cut and treated with diaminobenzidine after a presoak in cobalt chloride and counterstained with cresyl violet.

Efferent volley. Efferent innervation to the horizontal canal can often (but not always) be seen as a distinct white band lying within the anterior ramus of the VIIIth nerve. However, the efferent supply to the posterior canal is almost always visible as a distinct bundle that can be dissected peripherally to the ampulla (Highstein and Baker, 1986). Therefore, field potentials were recorded in this bundle using a low-impedance glass microelectrode to determine the range of shock rate over which efferent axons could follow the centrally applied stimulus. Figure $1 A$ shows the orthodromic field potentials recorded from the posterior canal efferent nerve evoked by central stimulation at $2 \times \mathrm{T}(200 / \mathrm{sec})$. Orthodromic following persists at shock rates up to $500 / \mathrm{sec}$, although the amplitude of the fields drops slightly, and was intermittent at $1 \mathrm{kHz}$.

Parameters of stimulation. The relationships between the stimulus shock rate and intensity and the induced effects on background discharges and rotational responses of 38 canal afferents were studied in 24 experiments to establish a standard experimental paradigm. Figure $1 B$ shows the facilitatory action of single-shock EVS stimulation (10$250 / \mathrm{sec}$ ) on the background discharge of a horizontal canal afferent. At shock rates between 20 and $200 / \mathrm{sec}$ the discharge increase was similar; higher or lower shock rates were less effective. Different combinations of pulse trains did not augment the response beyond that evoked by single trains presented within the effective range $(20-200 / \mathrm{sec})$. Similar parameters of stimulation facilitated the afferent's rotation-induced modulation, and therefore a midrange shock rate of $100 / \mathrm{sec}$ was selected as the standard. This shock rate corresponds well to the peak instantaneous firing rates of efferent neurons recorded during behavioral arousal, viz., $80-100 \mathrm{imp} / \mathrm{sec}$ (Highstein and Baker, 1985).

Stimulus intensity was adjusted to explore the possibility of recruiting efferent neurons with higher stimulus strengths. Once suprathreshold shock intensities were reached, no systematic increment or decrement of the efferent effect was observed by increasing shock intensity; large shock intensities about $20-50 \times \mathrm{T}$ often antidromically activated afferents, presumably by current spread. Therefore, shock intensity was limited to $8 \times \mathrm{T}$.

Next, at these parameters the relative effectiveness of ipsi- and contralateral EVS activation was surveyed by shifting the pulses between pairs of stimulating electrodes. Contralateral stimulation was frequently the least effective, but no significant distinction between electrode pairs could be made. Thus shocks between the pairs straddling the midline were applied to evoke a bilateral EVS activation.

\section{Caloric stimulation of the labyrinth}

In 12 experiments a caloric stimulus was applied to the labyrinth to produce a generalized increase in the afferent's rate. Here the head of the fish was pitched nose-down about $15^{\circ}$ to orient the horizontal canal in a slightly vertical plane. A small resistor was cemented to the bone overlying the common crus and DC current was applied across the resistor for 5-10 sec to heat it. Before and after the application of the caloric stimulus the afferent's rotational responses to cycles without (control) and in combination with electrical EVS activation were examined. Caloric stimulation was often repeated at about 1 -min intervals to effect a cumulative increase in the afferent's rate, and rotational tests were done at each increment to compare the responses at different rates.

\section{Results}

The influence of EVS activation on the background and induced discharges of 158 afferents was analyzed. Of these afferents, 14 were successfully tested before, during, and after behavioral activation of the EVS in the alert paradigm, and 144 were studied using electrical EVS stimulation. A facilitatory action was observed in 154 afferents; 4 had an inhibitory response to electrical EVS stimulation and will be discussed separately. The sign of the responses evoked by electrical stimulation could not be changed by alternating the pulses between the different stimulating wires, reversing the polarity, or by varying the shock rate or intensity.

\section{Efferent action on background discharge}

The facilitatory action of electrical EVS stimulation on the background discharge of 6 afferents is shown in Figure 2. Duration of EVS stimulation is marked by arrows and varied from 18.5 $\sec (A)$ to $50 \mathrm{sec}(F)$. A rate increase was detectable usually within 10-20 msec of onset and peak rates were reached within 2-4 sec. Figure 2, $A$ and $B$, are examples of low-gain afferents. EVS stimulation raised the rate slightly from 38 to a steady 42.5 $\mathrm{imp} / \mathrm{sec}$ in $A$ and from 53 to a steady $60.5 \mathrm{imp} / \mathrm{sec}$ in $B$. By contrast, in the examples of high-gain $(C$ and $D)$ and acceleration $(E$ and $F)$ afferents the rate increase was striking, and per- and postchanges were observed. Pcak rates wcre usually followed by a decline that plateaued after prolonged stimulation. For example, in $F$. EVS stimulation increased the rate from 42 to a maximum of $147 \mathrm{imp} / \mathrm{sec}$, followed by a decline to a steady 114 $\mathrm{imp} / \mathrm{sec}$. In some cases (e.g., $2 E$ ) the rate remained elevated after termination of the stimulus.

Figure 3 graphs the evoked rate of the 140 afferents excited by electrical EVS stimulation and the corresponding background (control) rate; evoked data were measured during the steady portion of the response (cf. Fig. 2, C-F). Control rate of lowgain afferents varied from 17.2 to $105.2 \mathrm{imp} / \mathrm{sec}$. Because the spacing of their interspike intervals, as measured by the $\mathrm{CV}$, was consistently regular, ranging from 0.04 to 0.1 (see Table 1), they are grouped as one population. High-gain and acceleration afferents have broad ranges of control rate and $\mathrm{CV}$, ranging from 0.7 to $131 \mathrm{imp} / \mathrm{sec}$ and 0.04 to 1.22 and from 1.4 to $115.6 \mathrm{imp} /$ scc and 0.08 to 0.9 , respectively; therefore, these afferents are each subdivided into $\mathrm{R}$ or regular $(\mathrm{CV} \leq 0.1)$, $\mathrm{M}$ or intermediate $(0.1<\mathrm{CV}<0.4)$, and I or irregular $(\mathrm{CV} \geq 0.4)$ afferents. Figure $3 A$ shows that across the range of control rate the efferent-evoked 
rate (Efferent Rate) of high-gain and acceleration afferents was usually larger than that of low-gain afferents, and Figure $3 B$ reveals that the EVS-cvoked rate increase is most pronounced on high-gain (open triangles) and acceleration (open squares) afferents having low control rates with irregular interspike intervals.

The left-hand side of Table 1 lists the averaged results of electrical EVS stimulation on the background discharge of the 140 afferents separated into low-gain ( $n=38,27.1 \%)$, high-gain $(n=70,50 \%)$, and acceleration $(n=32,22.9 \%)$ afferents. $\mathrm{R}$, $\mathrm{M}$, and $\mathrm{I}$ high-gain and acceleration afferents are also listed.

The 38 low-gain afferents had an averaged control rate of 48.2 $\pm 14.7 \mathrm{imp} / \mathrm{sec}$; a $12 \mathrm{imp} / \mathrm{sec}(25 \%)$ increase to $60.2 \pm 19.4$ $\mathrm{imp} / \mathrm{sec}$ was evoked by EVS stimulation. EVS stimulation raised the averaged control rates of the $21 \mathrm{R}$ and $23 \mathrm{M}$ high-gain afferents by $16.8(25 \%)$ and $15.9(46 \%) \mathrm{imp} / \mathrm{sec}$, respectively, and the spacings of their interspike intervals were little affected. For the $26 \mathrm{I}$ high-gain afferents the averaged control rate was elevated by $19.1 \mathrm{imp} / \mathrm{sec}$ (or 4-fold) during EVS stimulation; although EVS stimulation did not change an irregular afferent $(\mathrm{CV} \geq 0.4)$ into one with a regular pattern $(\mathrm{CV} \leq 0.1)$, a consistent increase in the regularity of discharge (or a lowering of the $\mathrm{CV}$ from $0.68 \pm 0.23$ to $0.38 \pm 0.23$ ) was observed. A similar percent increase was observed for the different subgroups of the 32 acceleration afferents: a $24(25 \%), 33.3(60 \%)$, and 52.9 (or 5 -fold) $\mathrm{imp} / \mathrm{sec}$ increase was measured in the $4 \mathrm{R}, 9$ $\mathrm{M}$, and $19 \mathrm{I}$ acceleration afferents, respectively; regularity of discharge was little affected in acceleration afferents.

In summary, electrical EVS stimulation raised the afferents' averaged background rate by $21.9 \mathrm{imp} / \mathrm{sec}(58 \%)$. This facilitation was more pronounced on high-gain and acceleration afferents, particularly on those having low rates with irregular interspike intervals, than on the population of low-gain afferents. A similar, although not identical, relationship between the afferent's response magnitude of efferent facilitation and discharge regularity has been described for the squirrel monkey (Goldberg and Fernandez, 1980).

\section{Efferent action on rotation-induced responses of afferents}

Behavioral EVS activation. Figure 4 gives 2 examples of the EVS action elicited behaviorally on the afferent's response to sinusoids. In $A$ (arrow), the fish displayed the initial postural reactions, viz., fin flaring, and then, in later cycles not shown, attempted to swim. Prior to efferent activation the discharge of this high-gain afferent occurred over only $62.1 \%$ of the stimulus cycle, and the average rate $(22 \mathrm{imp} / \mathrm{sec})$ and the $\mathrm{DC}$ firing rate $(15.5 \mathrm{imp} / \mathrm{sec})$ were unequal. During the early phases of the behavioral reflex, the average rate rose dramatically to $135 \mathrm{imp} /$ $\mathrm{sec}$, now equal to the DC firing rate, and the percent conduction of discharge became $100 \%$, thus changing the response to a complete, bidirectional modulation. In $B$ the response of this acceleration I afferent was modulated throughout the control cycles. The behavioral reaction of the fish on approach of the probe was brief and only a slight flaring of the fins was observed. At this near-threshold of the behavioral reflex the firing rate rose by only $5 \mathrm{imp} / \mathrm{sec}$. In both cases $(A$ and $B$ ), however, the sensitivity decreased during EVS activation.

The left-hand column of Figure $5(A-D)$ shows the responses of 4 high-gain afferents to rotational stimuli before (blackened histograms) and during (whitened histograms) behavioral EVS activation. In all cases the DC firing rate of control responses (dotted lines) was increased by EVS activation (solid lines). This
A

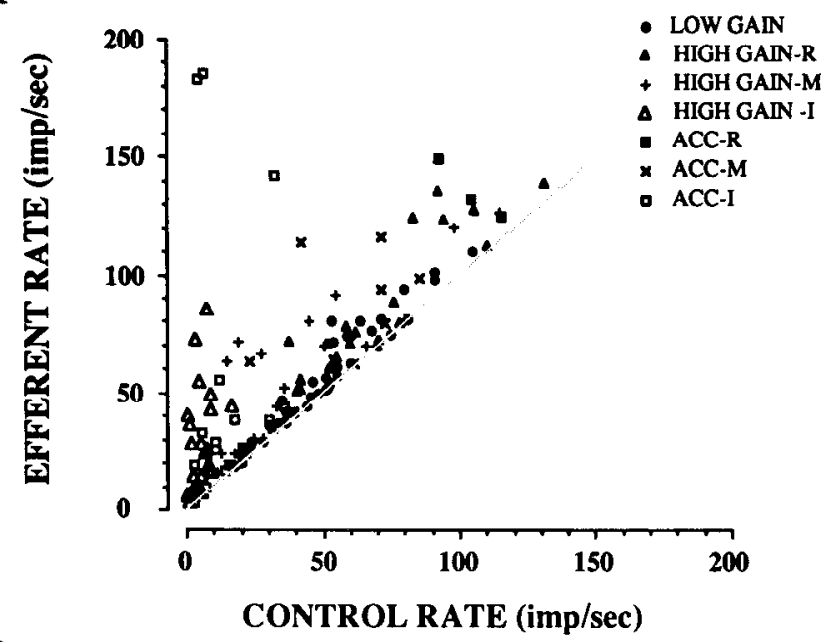

B

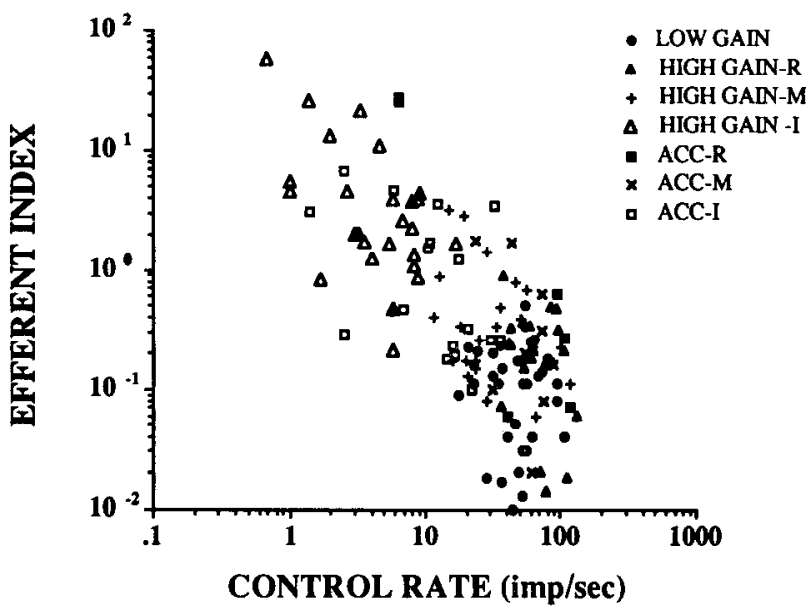

Figure 3. Effect of efferent stimulation on background discharge of 140 afferents; symbols represent the different afferents grouped into lowgain, high-gain, and acceleration afferents, and the latter 2 groups into divisions based on the regularity of discharge into $R, M$, and I afferents. $A$, The control rate (abscissa) of cach afferent is plotted against the rate evoked by efferent stimulation (efferent rate, ordinate); a line of slope 1 is drawn and indicates equal values for both rates. $B, \log -\log$ plot of efferent index as a function of the control rate; efferent index is the efferent rate minus the control rate divided by the control rate (from $A$ ), and indicates the relative change evoked by efferent stimulation is larger for the afferents having low rates, namely the irregular high-gain and acceleration afferents (open symbols).

rate increase was sufficient to prevent discharge silencing over the half-cycle in the off-direction of rotation in two cases $(B$ and $D)$ and to expand the time of impulse conduction from 80 to $95 \%$ of the rotation cycle in $A$ and from 35 to $74.5 \%$ in $C$. In Figure $5 D$ (same afferent as Fig. $4 A$ ) the afferent was successfully recorded over several cycles while the fish attempted to swim and the DC firing rate rose from 15.5 to $174 \mathrm{imp} / \mathrm{sec}$. However, the responses observed were not uniform over the course of EVS activation and only selected cycles recorded are presented. During the onsct of the bchavioral reflex, the ratc may increase abruptly over any portion of the stimulus cycle and dramatically change the response phase, particularly at high frequencies of rotation. Because the magnitude and duration of the behavioral reflex are uncontrolled, and selection of stimulus cycles is somewhat arbitrary, a reliable and quantitative estimate of the change 
Table 1. Action of electrical EVS stimulation on background and rotation-induced discharges of horizontal canal afferents

\begin{tabular}{|c|c|c|c|c|c|c|c|c|c|c|c|c|c|c|}
\hline \multirow{2}{*}{\multicolumn{2}{|c|}{$\begin{array}{l}\text { CELL } \\
\text { TYPE }\end{array}$}} & \multirow[b]{2}{*}{$\mathbf{N}$} & \multirow[b]{2}{*}{ CONDITION } & \multicolumn{2}{|c|}{ BACKGROUND } & \multicolumn{9}{|c|}{ RESPONSE TO ROTATION } \\
\hline & & & & $\mathbf{C V}$ & $\begin{array}{l}\text { RATE } \\
\text { (ips) }\end{array}$ & $\begin{array}{l}\text { STIMULUS } \\
\text { VELOCITY }\end{array}$ & $\begin{array}{c}\text { STMUULUS } \\
\mathrm{Hz}\end{array}$ & $\begin{array}{l}\mathrm{DC} \\
(\mathrm{lps})\end{array}$ & $\begin{array}{c}\text { RATE } \\
\text { (lps/cycle) }\end{array}$ & \begin{tabular}{|c|} 
SENSITIV- \\
ITY
\end{tabular} & $\begin{array}{c}\text { PHASE } \\
\text { (deg) }\end{array}$ & \begin{tabular}{|c|} 
PEAK \\
RATE (ips)
\end{tabular} & \begin{tabular}{|c|} 
\% CON- \\
DUCTION
\end{tabular} & \begin{tabular}{|c|}
$\mathbf{N}$ \\
CUT.OFF
\end{tabular} \\
\hline \multirow{2}{*}{\multicolumn{2}{|c|}{$\begin{array}{l}\text { LOW } \\
\text { GAIN }\end{array}$}} & \multirow{2}{*}{$\begin{array}{c}38 \\
(27.1 \%)\end{array}$} & CONTROL & $\begin{array}{l}0.073 \\
(0.02) \\
\end{array}$ & $\begin{array}{r}48.2 \\
(14.7) \\
\end{array}$ & \multirow{2}{*}{$\begin{array}{l}16.4 \\
(7.6)\end{array}$} & \multirow{2}{*}{$\begin{array}{c}0.36 \\
(0.16)\end{array}$} & $\begin{array}{r}49.4 \\
(22.3) \\
\end{array}$ & $\begin{array}{r}49.4 \\
(22.3) \\
\end{array}$ & $\begin{array}{c}0.50 \\
(0.23) \\
\end{array}$ & $\begin{array}{c}2.2 \\
(10.3)\end{array}$ & $\begin{array}{c}59.9 \\
(23.9) \\
\end{array}$ & $\begin{array}{l}100 \\
(0)\end{array}$ & 0 \\
\hline & & & EFFERENT & $\begin{array}{l}0.075 \\
(0.03)\end{array}$ & $\begin{array}{c}60.2 \\
(19.4)\end{array}$ & & & $\begin{array}{c}54.7 \\
(25.3)\end{array}$ & $\begin{array}{r}54.7 \\
(25.3) \\
\end{array}$ & $\begin{array}{c}0.48 \\
(0.25)\end{array}$ & $\begin{array}{c}2.7 \\
(8.8)\end{array}$ & $\begin{array}{c}65.1 \\
(26.1)\end{array}$ & $\begin{array}{l}100 \\
(0)\end{array}$ & 0 \\
\hline \multirow{4}{*}{$\begin{array}{l}Z \\
z \\
z \\
z\end{array}$} & $\mathbf{R}$ & $\begin{array}{c}21 \\
(15 \%)\end{array}$ & CONTROL & $\begin{array}{l}0.074 \\
(0.02)\end{array}$ & $\begin{array}{c}68.3 \\
(27.5)\end{array}$ & $\begin{array}{l}12.8 \\
(7.1)\end{array}$ & $\begin{array}{c}0.39 \\
(0.13)\end{array}$ & $\begin{array}{r}67.9 \\
(32.1)\end{array}$ & $\begin{array}{r}67.9 \\
(32.1) \\
\end{array}$ & $\begin{array}{r}3.49 \\
(2.61)\end{array}$ & $\begin{array}{c}20.1 \\
(14.5)\end{array}$ & $\begin{array}{l}105.1 \\
(40.6)\end{array}$ & $\begin{array}{l}100 \\
(0)\end{array}$ & 0 \\
\hline & \multirow{2}{*}{$\mathbf{M}$} & \multirow{2}{*}{$\begin{array}{c}23 \\
(16.4 \%)\end{array}$} & CONTROL & $\begin{array}{c}0.22 \\
(0.09) \\
\end{array}$ & $\begin{array}{r}34.5 \\
(27.8) \\
\end{array}$ & \multirow{2}{*}{$\begin{array}{l}11.7 \\
(5.5)\end{array}$} & \multirow{2}{*}{$\begin{array}{c}0.43 \\
(\mathbf{0 . 1 2})\end{array}$} & $\begin{array}{r}31.3 \\
(36.1) \\
\end{array}$ & $\begin{array}{r}39.3 \\
(29.8) \\
\end{array}$ & $\begin{array}{r}2.95 \\
(2.65) \\
\end{array}$ & $\begin{array}{r}19.5 \\
(18.2) \\
\end{array}$ & $\begin{array}{r}68.4 \\
(49.0) \\
\end{array}$ & $\begin{array}{r}82.0 \\
(23.7) \\
\end{array}$ & $\begin{array}{c}10 \\
(43.5 \%)\end{array}$ \\
\hline & & & EFFERENT & $\begin{array}{r}0.19 \\
(0.14) \\
\end{array}$ & $\begin{array}{r}50.4 \\
(\mathbf{3 3 . 8}) \\
\end{array}$ & & & $\begin{array}{r}49.0 \\
(36.8)\end{array}$ & $\begin{array}{r}50.4 \\
(36.7) \\
\end{array}$ & $\begin{array}{r}2.10 \\
(2.01) \\
\end{array}$ & $\begin{array}{r}18.9 \\
(16.9)\end{array}$ & $\begin{array}{r}74.5 \\
(52.7) \\
\end{array}$ & $\begin{array}{r}93.5 \\
(12.7) \\
\end{array}$ & $\begin{array}{c}5 \\
(21.7 \%)\end{array}$ \\
\hline & $\mathbf{I}$ & $\begin{array}{c}26 \\
(18.9 \%)\end{array}$ & CONTROL & $\begin{array}{r}0.68 \\
(0.23) \\
\end{array}$ & $\begin{array}{c}6.4 \\
(14.6)\end{array}$ & $\begin{array}{l}13.5 \\
(6.6)\end{array}$ & $\begin{array}{c}0.42 \\
(0.15)\end{array}$ & $\begin{array}{r}-16.2 \\
(36.4)\end{array}$ & $\begin{array}{r}10.6 \\
(9.6)\end{array}$ & $\begin{array}{c}3.68 \\
(3.28)\end{array}$ & $\begin{array}{c}24.8 \\
(12.2)\end{array}$ & $\begin{array}{c}30.1 \\
(20.2)\end{array}$ & $\begin{array}{c}47.7 \\
(22.2)\end{array}$ & $\begin{array}{c}24 \\
(92.3 \%)\end{array}$ \\
\hline \multirow{5}{*}{ 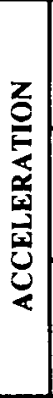 } & $\mathbf{R}$ & (2.9\%) & EFFERENT & $\begin{array}{c}0.09 \\
(0.01) \\
\end{array}$ & $\begin{array}{r}109.8 \\
(52.2) \\
\end{array}$ & $\begin{array}{r}16.7 \\
(10.5)\end{array}$ & $\begin{array}{c}0.30 \\
(0.16)\end{array}$ & $\begin{array}{l}108.0 \\
(50.8) \\
\end{array}$ & $\begin{array}{l}108.0 \\
(50.8) \\
\end{array}$ & $\begin{array}{r}4.11 \\
(2.98) \\
\end{array}$ & $\begin{array}{r}61.6 \\
(9.4) \\
\end{array}$ & $\begin{array}{l}155.4 \\
(76.8) \\
\end{array}$ & $\begin{array}{l}100 \\
(0)\end{array}$ & $\mathbf{0}$ \\
\hline & \multirow{2}{*}{$\mathbf{M}$} & \multirow{2}{*}{$\begin{array}{c}9 \\
(6.4 \%)\end{array}$} & CONTROL & $\begin{array}{c}0.20 \\
(0.08) \\
\end{array}$ & $\begin{array}{r}52.3 \\
(30.8) \\
\end{array}$ & \multirow{2}{*}{$\begin{array}{l}16.8 \\
(8.3)\end{array}$} & \multirow{2}{*}{$\begin{array}{c}0.38 \\
(0.12)\end{array}$} & $\begin{array}{r}51.2 \\
(27.7)\end{array}$ & $\begin{array}{c}61.2 \\
(22.5) \\
\end{array}$ & $\begin{array}{r}5.59 \\
(2.87) \\
\end{array}$ & $\begin{array}{r}65.6 \\
(10.9)\end{array}$ & $\begin{array}{l}130.4 \\
(41.5) \\
\end{array}$ & $\begin{array}{r}75.8 \\
(18.2) \\
\end{array}$ & $\begin{array}{c}7 \\
(77.8 \%) \\
\end{array}$ \\
\hline & & & EFFERENT & $\begin{array}{c}0.22 \\
(0.07) \\
\end{array}$ & $\begin{array}{r}85.6 \\
(29.5) \\
\end{array}$ & & & $\begin{array}{r}81.3 \\
(28.3) \\
\end{array}$ & $\begin{array}{r}81.9 \\
(28.1) \\
\end{array}$ & $\begin{array}{r}3.36 \\
(1.48) \\
\end{array}$ & $\begin{array}{l}64.8 \\
(9.6) \\
\end{array}$ & $\begin{array}{r}132.3 \\
(38.4) \\
\end{array}$ & $\begin{array}{l}97.5 \\
(7.4) \\
\end{array}$ & $\begin{array}{c}1 \\
(11.1 \%)\end{array}$ \\
\hline & \multirow{2}{*}{$\mathbf{I}$} & \multirow{2}{*}{$\begin{array}{c}19 \\
(13.6 \%)\end{array}$} & CONTROL & $\begin{array}{r}0.60 \\
(0.17)\end{array}$ & $\begin{array}{r}13.3 \\
(12.5)\end{array}$ & 14.4 & 0.42 & $\begin{array}{c}-15.1 \\
(36.3)\end{array}$ & $\begin{array}{c}23.0 \\
(34.3)\end{array}$ & $\begin{array}{c}7.19 \\
(4.89)\end{array}$ & $\begin{array}{c}672 \\
(13.0)\end{array}$ & $\begin{array}{c}72.0 \\
(40.0)\end{array}$ & $\begin{array}{c}46.2 \\
(19.1)\end{array}$ & $\begin{array}{c}18 \\
(94.7 \%)\end{array}$ \\
\hline & & & EFFERENT & $\begin{array}{c}0.53 \\
(0.23)\end{array}$ & $\begin{array}{c}66.2 \\
(42.3)\end{array}$ & & & $\begin{array}{c}31.7 \\
(31.5)\end{array}$ & $\begin{array}{c}65.8 \\
(66.2) \\
\end{array}$ & $\begin{array}{r}4.46 \\
(3.71)\end{array}$ & $\begin{array}{r}69.6 \\
(14.2)\end{array}$ & $\begin{array}{r}88.5 \\
(56.8)\end{array}$ & $\begin{array}{r}77.8 \\
(20.6)\end{array}$ & $\begin{array}{c}14 \\
(73.7 \%)\end{array}$ \\
\hline Al & & 140 & CONTROL & $\begin{array}{c}0.29 \\
(0.19) \\
\end{array}$ & $\begin{array}{r}37.9 \\
(34.1) \\
\end{array}$ & 14.3 & 0.39 & $\begin{array}{r}30.0 \\
(46.2)\end{array}$ & $\begin{array}{c}41.9 \\
(36.5)\end{array}$ & $\begin{array}{c}3.31 \\
(\mathbf{3 . 7 8}) \\
\end{array}$ & $\begin{array}{c}26.6 \\
(31.8)\end{array}$ & $\begin{array}{c}73.7 \\
(47.3) \\
\end{array}$ & $\begin{array}{c}78.6 \\
(27.5) \\
\end{array}$ & $\begin{array}{c}59 \\
(42.1 \%)\end{array}$ \\
\hline
\end{tabular}

For each cell type, $n$ is the number of afferents (\% of total) studied. For each condition (control and efferent) mean values ( \pm SD) are given of the CV and rate (imp/ $\mathrm{sec})$ of the background discharge, stimulus velocity $(\% / \mathrm{sec})$ and frequency $(\mathrm{Hz}), \mathrm{DC}$ and average rate $(\mathrm{imp} / \mathrm{sec})$, sensitivity (imp/sec per $\%$ sec), phase $\left({ }^{\circ}\right)$, peak rate (imp/ $\mathrm{sec})$, and percent $(\%)$ conduction of discharge over cycle time of the rotational responses. Number of afferents displaying a cutoff response is listed, with their percentage of total in that afferent group in parentheses.

in afferents' response at different amplitudes and frequencies of rotation could not be made.

Electrical EVS activation. The right-hand column of Figure $5(E-H)$ shows the responses to sinusoids of 4 afferents analyzed before (blackened histograms) and in combination with electrical EVS stimulation (whitened histograms). Note in the figure the similarity of results obtained using behavioral activation (left side) and electrical stimulation (right side) of the EVS.

Figure $5 E$ shows the responses of a low-gain afferent; in control cycles the afferent's average and DC firing rates were equivalent to its background rate $(68.2 \mathrm{imp} / \mathrm{sec} ; \mathrm{CV}=0.06)$. EVS stimulation raised the background rate to $76.4 \mathrm{imp} / \mathrm{sec}(\mathrm{CV}=$ 0.05 ) and the average and DC firing rates by a comparable amount to $76.9 \mathrm{imp} / \mathrm{sec}$. Response sensitivities for both tests were nearly identical (control $=0.64$; experimental $=0.62 \mathrm{imp} /$ sec per $\%$ sec).

Figure $5 F$ shows the responses of a regularly discharging high-gain (R) afferent. EVS stimulation increased the background rate and the average and DC firing rates by equivalent amounts, from $41.7(\mathrm{CV}=0.07)$ to $54.8(\mathrm{CV}=0.08)$ and from 40.9 to $50.9 \mathrm{imp} / \mathrm{sec}$, respectively. Note that while the average rate rose by $25 \%$ during EVS stimulation, the peak rate (about
$85 \mathrm{imp} / \mathrm{sec}$ ) did not change appreciably. Thus the sensitivity fell by roughly $25 \%$, from 4.37 to $3.18 \mathrm{imp} / \mathrm{sec}$ per $\% \mathrm{sec}$. This reduction in response sensitivity was not the result of EVS stimulation driving the afferent to an upper rate limit because at a higher frequency of rotation $(0.5 \mathrm{~Hz}$, not shown) the peak rate reached $119.6 \mathrm{imp} / \mathrm{sec}$.

More pronounced effects of EVS stimulation can be seen in the responses of the high-gain (I) afferent in Figure $5 G$, which had a low rate $(2.0 \mathrm{imp} / \mathrm{sec})$ and irregular pattern $(\mathrm{CV}=0.84)$ of background discharge. EVS stimulation increased the background rate to $41.2 \mathrm{imp} / \mathrm{sec}(\mathrm{CV}=0.52)$. This afferent's control DC firing rate was $1.4 \mathrm{imp} / \mathrm{sec}$ and its discharge occurred over only $51.6 \%$ of the stimulus cycle; during EVS stimulation, the DC firing rate rose by $49.8 \mathrm{imp} / \mathrm{sec}$ and the response became $100 \%$ bidirectional. The peak rate also increased during EVS stimulation but by a lesser amount of $37.1 \mathrm{imp} / \mathrm{sec}$, and thus the sensitivity dropped.

The responses of an acceleration (M) afferent are shown in Figure $5 H$ (same cell as Fig. $2 F$ ). EVS stimulation raised the background rate from $42(\mathrm{CV}=0.19)$ to $114(\mathrm{CV}=0.11) \mathrm{imp} /$ sec, and elevated the DC firing rate by $78.3 \mathrm{imp} / \mathrm{sec}$ (from 41.4 to $119.7 \mathrm{imp} / \mathrm{sec}$ ) and converted the response in control cycles 
(62.1\% conduction) into a bidirectional response. Again, the increase in peak rate $(32 \mathrm{imp} / \mathrm{sec}$ ) was disproportionate to that of the DC rate and the sensitivity fell.

\section{Response dynamics to rotation during efferent stimulation}

Frequency domain. Bode plots of response re: velocity of lowgain (circles, $n=19$ ), high-gain (triangles, $n=22$ ), and acceleration (diamonds, $n=11$ ) afferents are presented in Figure 6. Open symbols are the averaged response of each afferent group to control cycles, and filled symbols are the same afferents' response to rotations in combination with electrical EVS stimulation. A morc complcte description of the afferents' individual response dynamics without efferent stimulation can be found in the preceding study (Boyle and Highstein, 1990).

In the upper graph of Figure 6 the phase of response for each afferent group was not altered by EVS stimulation. The lower graph plots the afferents' averaged response sensitivity. The sensitivity of low-gain afferents is nearly linearly related to stimulus velocity across the tested frequencies and is clearly unaffected by EVS stimulation. High-gain and acceleration afferents display a sensitivity that is frequency-dependent. EVS stimulation reduced the sensitivity by a consistent amount at all tests without changing the high-frequency sensitivity increase. Therefore, EVS stimulation rescales the gain without effecting the input-output transfer operations.

Amplitude domain. To determine whether EVS stimulation had a differential effect on the afferent's modulation to sinusoids in the amplitude domain, the responses of several low-gain, high-gain, and acceleration afferents were examined to rotations of various amplitudes of velocity across several decades of stimulus frequency. The results of a single acceleration afferent are presented in Figure 7. Responses were collected during control cycles (open symbols) and during combined EVS stimulation (filled symbols) at 3 stimulus amplitudes. The figure plots the percent conduction of discharge over the stimulus cycle and the DC firing rate versus stimulus frequency in the upper 2 graphs. The lower panels graph the response phase and sensitivity re: acceleration. The principal effect of EVS stimulation can be seen in the upper 2 graphs. Even for large-amplitude and high-frequency stimuli, where the DC firing rate of control cycles drops as the time of discharge conduction shortens, EVS stimulation produced a steady rate of about $70 \mathrm{imp} / \mathrm{sec}$. At this rate a bidirectional response ( $100 \%$ conduction) was seen for all tests, except at $4 \mathrm{~Hz}$ (solid circle). The phase, which is more closely associated with stimulus acceleration than velocity, was unaffected. The observed decrease in sensitivity was comparable at all tests, and thus EVS activation only rescales the gain without producing a differential effect at a given stimulus. Similar results were seen in the other afferents examined.

Nonlinearity. Response nonlinearity to sinusoids exists in some afferents in the form of silencing of discharge in the off-dircction of rotation. As seen in Figures 4, 5, and 7, and will be examined more closely in later sections, EVS activation improves the response linearity by producing in many afferents a bidirectional response. Another nonlinearity observed in some high-gain and acceleration afferents is an amplitude distortion of modulation for rotations in the on-direction (cf. Boyle and Highstein, 1990). In several cases EVS stimulation reduced the overall response nonlinearity observed during control cycles by producing a smoother, sinusoidally modulated and bidirectional discharge. However, in most afferents displaying an amplitude distortion at a particular stimulus, EVS stimulation increased the afferent's
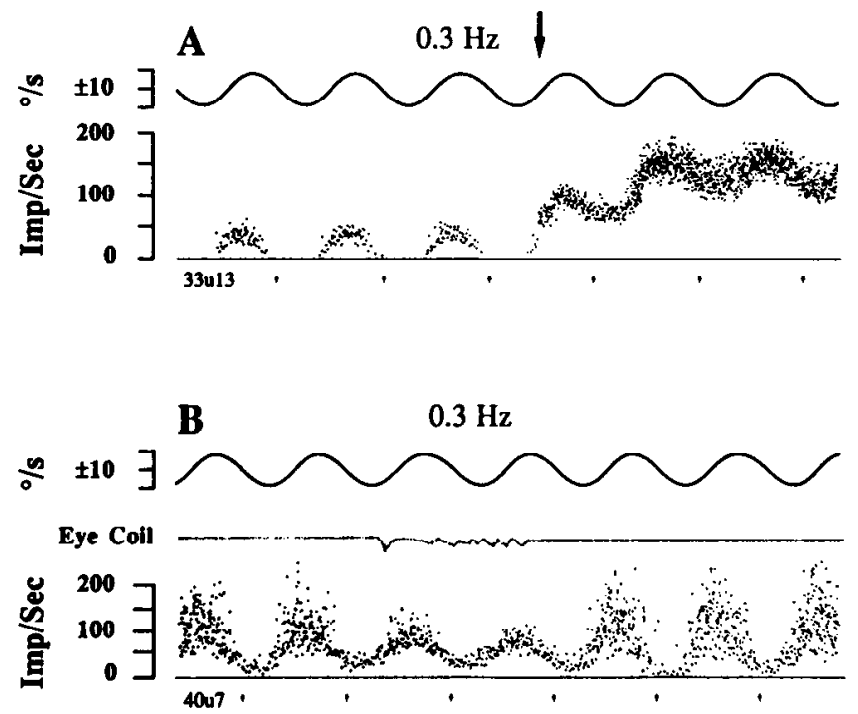

Figure 4. Effect of behavioral activation of efferent neurons on the rotation-induced responses of 2 horizontal canal afferents in the alert fish. In each frame the upper curve is the stimulus velocity profile, and the lower trace is the afferent's instantaneous firing rate; in $B$, the middle trace is a voltage trace of eye movement recorded using a magnetic search coil over the eye. Downward arrow in $A$ indicates the approximate start of behavioral reflex; the fish first elicited a flaring of the fins, and in later cycles (not shown) the fish attempted to swim. In $B$, the behavioral response was brief and consisted of eye movements and a slight flaring of the lateral fins.

rate without altering the response distortion. EVS stimulation by itself did not produce a response distortion by driving the afferent to an upper rate limit. If the afferent's modulation was sinusoidal over control cycles, it remained so during EVS stimulation.

Comparison of afferent responses. Table 1 compares the rotational responses of the 140 afferents in control cycles and in combination with electrical EVS stimulation. A single, midband frequency and amplitude stimulus was chosen for each afferent that excludes the amplitude distortion but may include the lower end discharge silencing.

Low-gain afferents $(n=38)$ had an averaged DC firing rate of $49.4 \mathrm{imp} / \mathrm{sec}$, and since the modulation occurred over the entire stimulus cycle ( $100 \%$ conduction) and was centered about its background level, the average rate per cycle was identical to the DC firing rate. EVS stimulation raised the average and DC firing rate to $54.7 \mathrm{imp} / \mathrm{sec}$. The peak rate rose by a comparable small amount during EVS stimulation, and thus the averaged sensitivity was similar to that measured during control cycles; response phase was unaffected. A general expression of EVS action on the response of low-gain afferents is: efferent response $=1.25 R$, where $R$ is the average rate of the control response.

For the 21 high-gain $(\mathrm{R})$ afferents, EVS stimulation raised the average and $\mathrm{DC}$ firing rate, but this increase was not matched by a proportionate increase in the peak rate and therefore the sensitivity fell by $17 \%$; again, no phase changes were observed. EVS action on the responses of high-gain (R) afferents can be expressed as: efferent response $=1.21 R-0.17 S$, where $S$ is the averaged sensitivity of the control response.

Ten (or $43.5 \%$ ) of the 23 high-gain (M) afferents, having intermediate $\mathrm{CV}$ values, displayed a discharge silencing over a portion of the rotation cycle. EVS stimulation raised the rate sufficiently to prevent the discharge silencing in 5 of the 10 
A

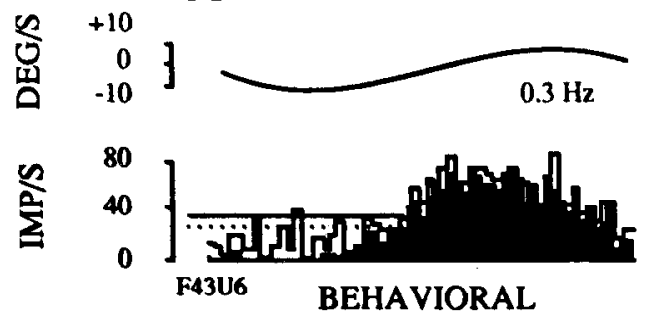

B

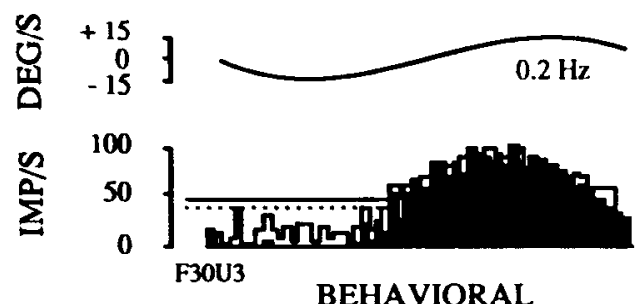

Figure 5. Cycle histograms compare alone (blackened histograms) with the response to combined rotation and efferent activation (open histograms) for 8 horizontal canal afferents; solid and dotted lines indicate the $\mathrm{DC}$ firing rates of response of open and blackened histograms, respectively (cycle histograms in Figs. 8-10 follow the same format). Upper trace in each example is the stimulus velocity profile; peak stimulus velocity (in $\% \mathrm{sec}$ ) and frequency are indicated. In the left-hand column $(A-D)$ EVS was cvoked by using a behavioral paradigm in the alert fish, and in the right-hand column $(E-H)$ electrical pulses were applied to the brain stem in the location of efferent neurons. Note the similarity of responses to efferent activation in the 2 paradigms.
C
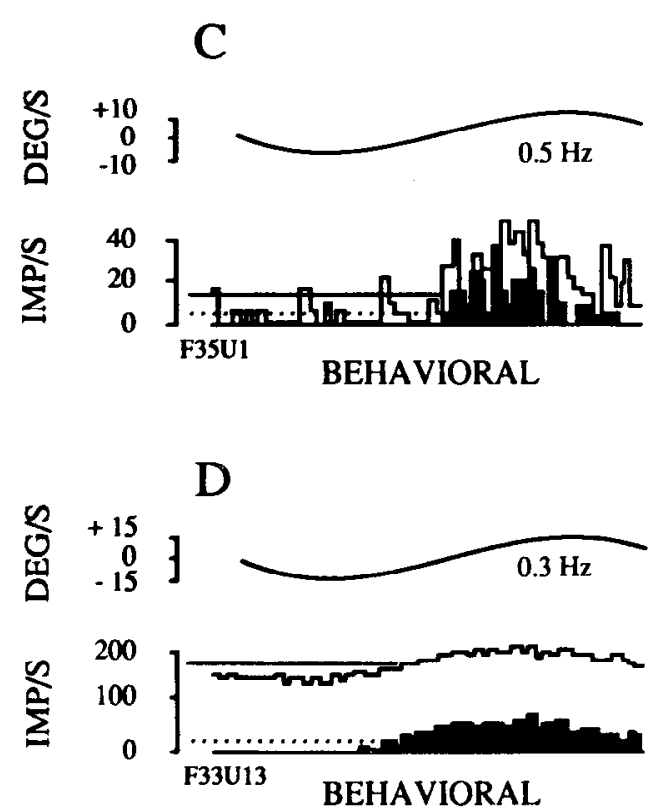
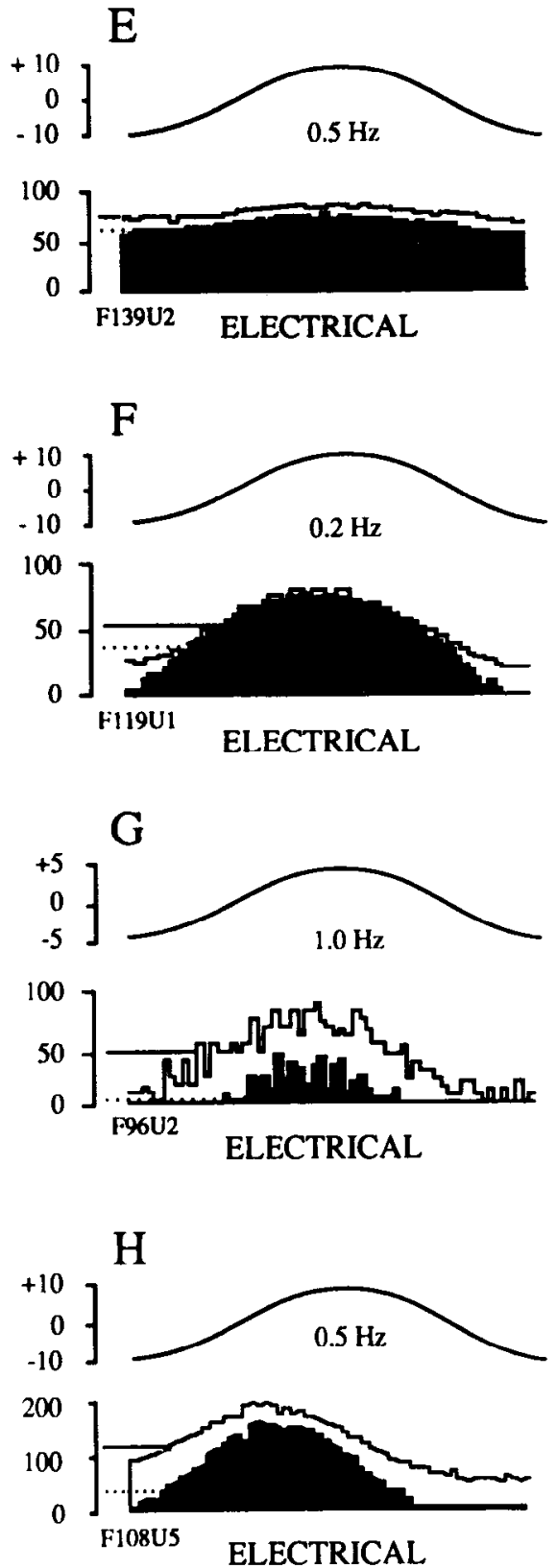

EI.ECTRICAL

ELECTRICAL afferents and extended the mean conduction time from 82.0 to $93.5 \%$ of the cycle. The peak rate rose by a lesser amount, and thus the sensitivity again dropped by $29 \%$. The efferent response of high-gain $(\mathrm{M})$ afferents can be generalized as: efferent response $=1.28 R-0.29 S+1.14 C$, where $C$ is the percent conduction of discharge modulation of the control response.

Within the population of high-gain afferents, the 26 (I) afferents, which have low rates and irregular discharge patterns (Background, Table 1), showed the greatest response to EVS stimulation. Of these afferents, 24 (or $92.3 \%$ ) showed a discharge silencing over a part of rotation cycle; the discharge was modulated on the average over less than one-half of the stimulus cycle, and thus the estimated DC, firing rate was less than zero.
EVS stimulation raised the DC firing rate and extended the time of impulse activity to $84.6 \%$ of the stimulus cycle. Half of the 24 afferents silenced during rotation developed a bidirectional response. A comparable increase in peak rate was not produced by EVS stimulation and thus the sensitivity fell by $46 \%$. A general expression of EVS action on the response of high-gain (I) afferents is: efferent response $=3.27 \mathrm{R}-0.46 \mathrm{~S}+1.77 \mathrm{C}$.

The responses of the $\mathrm{R}, \mathrm{M}$, and I subgroups of acceleration afferents to EVS stimulation were similar to those of the highgain afferents. The I acceleration afferents, which represent the majority of the acceleration affercnts $(19 / 32$, or $59 \%)$, werc the most influenced by EVS stimulation. Of the 19 (I) afferents, the discharge of 18 (or $94.7 \%$ ) was silenced over a large portion of 


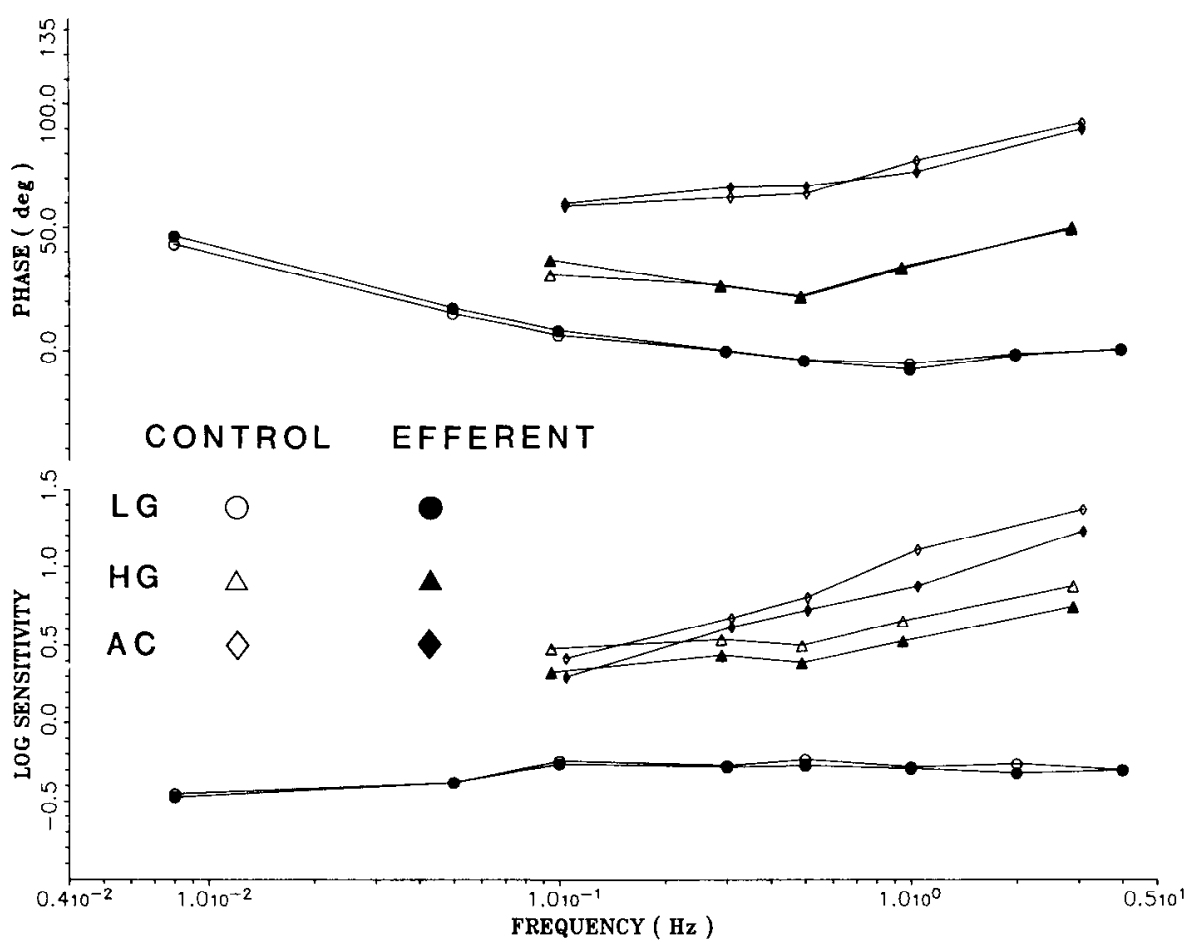

Figure 6. Bode plots of the averaged sensitivity $(\log \mathrm{imp} / \mathrm{sec} \mathrm{per} \% \mathrm{sec}$; lower graph) and phase (in ${ }^{\circ}$ re: stimulus velocity; upper graph) of response to rotation alone (open symbols) and combined electrical efferent stimulation (filled symbols) for low-gain (circles; $n$ $=19$ ), high-gain (triangles; $n=22$ ), and acceleration (diamonds; $n=11$ ) afferents. Note the phase of each afferent group to sinusoids remains unaffected by efferent stimulation. Vertical bars, $\pm \mathrm{SD}$. the rotation cycle; the averaged percent conduction was $46.2 \%$ and thus the estimated mean DC firing rate was less than zero. EVS stimulation raised the DC firing rate and lengthened the time of discharge conduction to $77.2 \%$. The response modulation about the increased DC firing rate was not simply shifted upward, and thus the sensitivity fell by $38 \%$. The phase, which maintains a closer temporal relationship to acceleration than to velocity, was unaffected. EVS action on the responses of acceleration $(\mathrm{I})$ afferents is: efferent response $=2.86 R-0.38 S+$ $1.68 C$.

In summary, in cases in which the afferent exhibits a discharge silencing over the rotation cycle, the efferent-induced rate increase effectively improves the information content carried by the afferent in the off-direction of rotation by providing a bidirectionality to the response. However, except for low-gain afferents, the rate increase is not matched by an increase of equal proportion in the peak rate; as a result the magnitude of response declines. EVS action on the averaged population response can be approximated as: efferent response $=1.41 R-0.33 S+1.18 C$. Another point from Table 1 needs to be considered. Compare the background rate (imp/sec) on the left-hand side to the average rate (imp/sec per cycle) on the right-hand side of Table 1 for control and efferent conditions for each afferent group. The values are about the same, indicating that the EVS action provides an equivalent rate increase when the animal is either at rest or in motion.

\section{Caloric stimulation}

The results presented so far have indicated that the major influence of EVS activation is a generalized rate increase, particularly on afferents having low resting rates. Another action of the EVS appears to be a decrease in the afferent's response sensitivity; this gain reduction may be secondary to the rate increase or independent of it. Before examining this another issue needs to be considered. For afferents that maintain a dis- charge over the entire stimulus cycle, the sensitivity can be reasonably measured. However, an increasingly less reliable estimate of the sensitivity results as the discharge occurs over a smaller portion of the stimulus cycle, and this is particularly the case for low-rate high-gain and acceleration afferents that are quickly driven to silence by rotation in the off-direction.

To determine whether the reduction in sensitivity observed during EVS stimulation was due to an overestimation of the depth of modulation in control cycles for afferents displaying a discharge silencing, a caloric stimulus was applied to the labyrinth to raise the afferent's discharge to a rate that revealed a full-cycle modulation. Typical results are presented in Figure 8. The afferent's responses to rotation alone (blackened histograms) and to rotation in combination with EVS stimulation (whitened histograms) are shown pre- and postcaloric. Consider first only the responses to control cycles of rotation. The response illustrated in $A$ occurred over only $58.2 \%$ of the cycle, and its estimated DC firing rate and sensitivity were $5.9 \mathrm{imp} /$ sec and $2.39 \mathrm{imp} / \mathrm{sec}$ per $\% / \mathrm{sec}$, respectively. In $B$, application of the first caloric stimulus shown elevated the rate to $35.9 \mathrm{imp} /$ sec and prevented the discharge silencing, but did not reduce the measured sensitivity $(2.36 \mathrm{imp} / \mathrm{sec}$ per $\% \mathrm{sec})$. Thus, the caloric stimulus shifted the center of response to a higher level revcaling a full-cyclc modulation, and the sensitivity of the afferent's original response appears to have been reliably estimated.

However, at higher rates of 61.5 and $87.3 \mathrm{imp} / \mathrm{sec}$ induced by added caloric stimulation in $C$ and $D$, the sensitivity dropped to 2.16 and $1.58 \mathrm{imp} / \mathrm{sec}$ per $\% \mathrm{sec}$, respectively. Thus it appears that elevation of afferent rate via the caloric mechanism can lower the gain to adequate stimulation. However, as shown below, EVS activation of afferents to levels matched by caloric stimuli lowers the afferent gain still further.

In the example of Figure 8 and in the 2 examples of Figure 9 the elevated rate produced by caloric stimulation was matched 

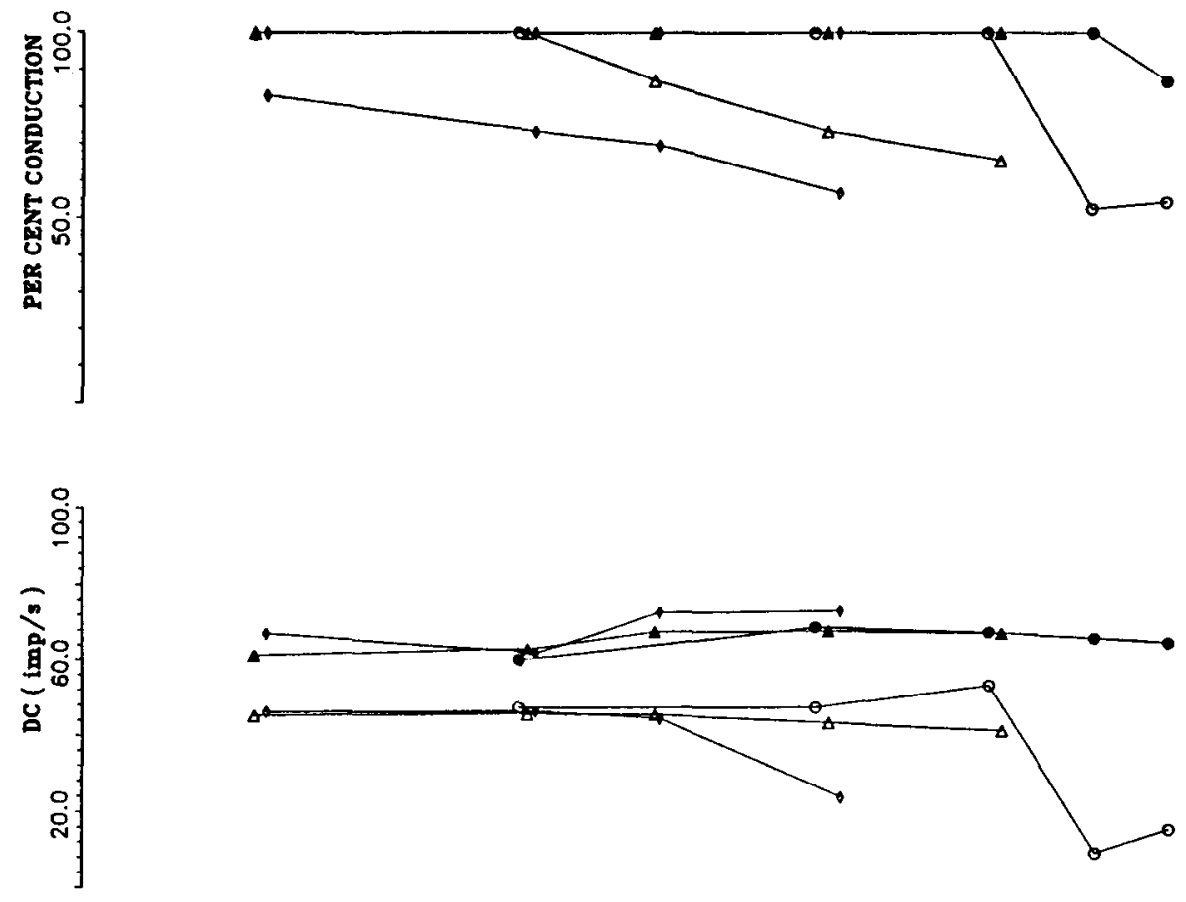

Figure 7. Responses of an acceleration afferent to control cycles (open symbols) and to combined electrical EVS stimulation (filled symbols) at amplitudes of 5 (circles), 10 (triangles), and 25 (diamonds) $\% \mathrm{sec}$ from $0.1-4.0 \mathrm{~Hz}$. The graphs are, from top to bottom: the time of discharge activity as a percent of stimulus cycle time (percent conduction), the $D C$, firing rate (in $\mathrm{imp} / \mathrm{sec}$ ), the phase (in ${ }^{\circ}$ re: stimulus acceleration, $0^{\circ}$ ), and, in the lowermost graph, the sensitivity (in $\mathrm{imp} / \mathrm{sec}$ per $\% / \mathrm{sec}^{2}$ ). Efferent stimulation produced a bidirectional response ( $100 \%$ conduction), except for the $5 \% / \mathrm{sec}$ stimulus at $4 \mathrm{~Hz}$, at all amplitudes of rotation by elevating the afferent's rate.
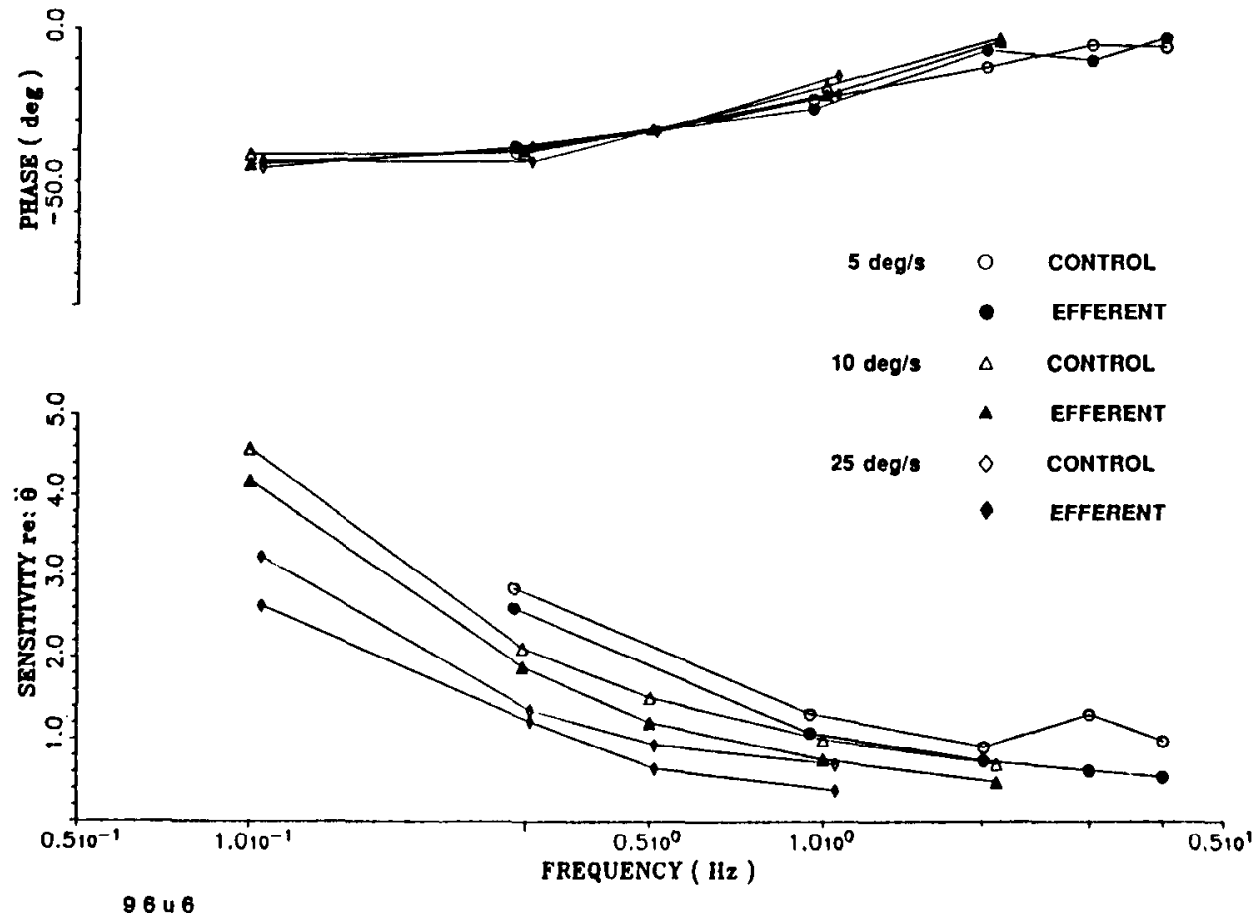

to a comparable rate increase evoked by EVS stimulation in the precaloric test. This allows the rotational responses in the 2 experiments to be compared at equivalent rates. Compare the response to combined rotation and EVS stimulation in Figure $8 A$ (whitened histogram) with that to control cycles after caloric stimulation in Figure $8 D$ (blackened histogram). In both cases the DC firing rates were similar $(81.5 \mathrm{imp} / \mathrm{sec}$ in $A$ and 87.3 $\mathrm{imp} / \mathrm{sec}$ in $D$ ), yet the sensitivity during precaloric EVS stimulation in $A(0.92 \mathrm{imp} / \mathrm{sec}$ per $\% / \mathrm{sec})$ was $58 \%$ lower than that of postcaloric control cycles in $D(1.58 \mathrm{imp} / \mathrm{sec}$ per $\% \mathrm{sec})$. This suggests that it is not only the elevation in rate that decreases afferent sensitivity but that there is an additional effect of EVS stimulation. Note in this afferent that the maximum rate increase evoked by caloric stimuli peaked at $87.3 \mathrm{imp} / \mathrm{sec}$ (shown in $D$ ), whereas EVS stimulation effected a further rate increase to $126.5 \mathrm{imp} / \mathrm{sec}$.

A similar result is shown for another afferent in Figure 9, $A$ and $B$. Consider the response to cycles with combined EVS stimulation in the precaloric condition (whitened histogram in A) with the response to control cycles in the postcaloric con- 


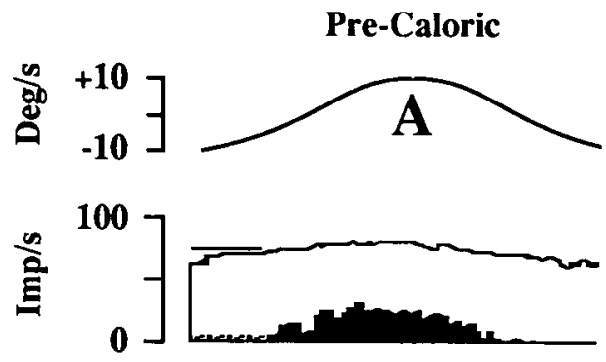

Post-Caloric

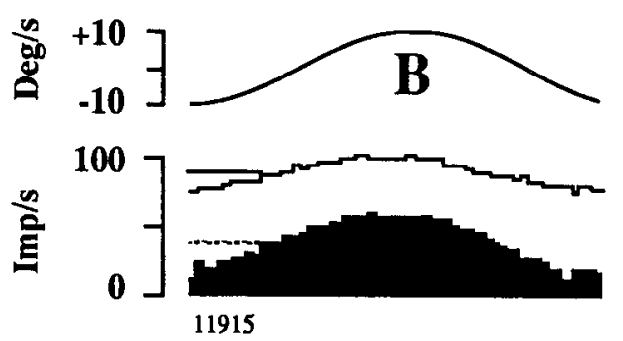

Post-Caloric
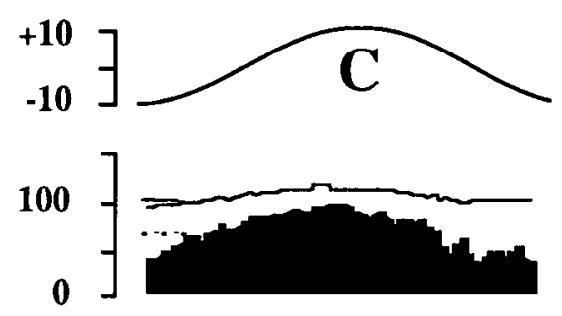

Figure 8. Effect of caloric stimulation on the responses of a high-gain afferent. Histograms are in the same format as Figure 5 and show the afferent's response to rotation alone and to combined efferent stimulation before (precaloric records, $A$ ) and after (postcaloric records, repetitive in $B-D$ ) a caloric stimulus was applied to the labyrinth. Upper trace in each panel is stimulus velocity profile, $\pm 10 \% / \mathrm{sec}, 0.5 \mathrm{~Hz}$. Note the different ordinate scales (in imp/sec) of the histograms. dition (blackened histogram in $B$ ). In control cycles in $B$, caloric stimulation raised the DC firing rate from 15.0 to $55.1 \mathrm{imp} / \mathrm{sec}$ and lowercd the sensitivity from 5.5 to $3.8 \mathrm{imp} / \mathrm{sec}$ per \% $/ \mathrm{sec}$. During EVS stimulation in the precaloric test in $A$, the DC firing rate rose to $53.6 \mathrm{imp} / \mathrm{sec}$, a rate similar to that produced by the caloric stimulus, but the sensitivity fell by a greater amount to $3.4 \mathrm{imp} / \mathrm{sec}$ per $\% \mathrm{sec}$; postcaloric EVS stimulation in $B$ produced a further rate increase to $68.8 \mathrm{imp} / \mathrm{sec}$ and reduction in sensitivity to $2.0 \mathrm{imp} / \mathrm{sec}$ per $\%$ sec.

In the previous examples caloric stimulation raised the afferent's rate, but at these higher rates the sensitivities also fell. However, for an equivalent rate increase EVS stimulation reduced the sensitivity by a greater amount than the caloric stimulus. Both records were from low-rate, irregular high-gain afferents. For afferents having a higher background rate caloric stimulation raised the rate, but did not cause a sensitivity re- duction. The responses of a regular high-gain afferent are shown in Figure 9, $C$ and $D$. EVS stimulation raised the afferent's background rate from $37.7(\mathrm{CV}=0.08)$ to $71.4(\mathrm{CV}=0.07)$ $\mathrm{imp} / \mathrm{sec}$. The average rate over the control cycles (blackened histogram in $C$ ) was doubled by caloric stimulation (blackened histogram in $D$ ) from 39.6 to $74.3 \mathrm{imp} / \mathrm{sec}$, but at this elevated rate the sensitivity was unchanged (precaloric $=1.66$; postcaloric $=1.72 \mathrm{imp} / \mathrm{sec}$ per $\% \mathrm{sec}$ ). In contrast, EVS stimulation alone in the precaloric test (whitened histogram in $C$ ) raised the discharge to a rate $(76.4 \mathrm{imp} / \mathrm{sec})$ equivalent to that produced by the caloric stimulus, but effected a sensitivity reduction (1.26 $\mathrm{imp} / \mathrm{sec} \mathrm{per} \% \mathrm{sec}$ ). EVS stimulation in the postcaloric condition (whitened histogram in $D$ ) elevated the rate to an even higher level of $104.0 \mathrm{imp} / \mathrm{sec}$, but did not further reduce the sensitivity $(1.21 \mathrm{imp} / \mathrm{sec}$ per $\% \mathrm{sec})$. Note that EVS stimulation raised the afferent's discharge at pre- and postcaloric rates by a similar
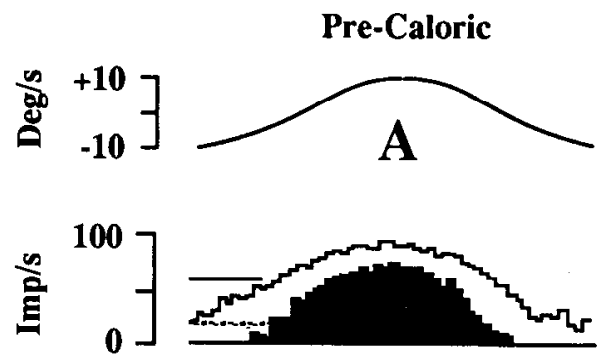

Post-Caloric
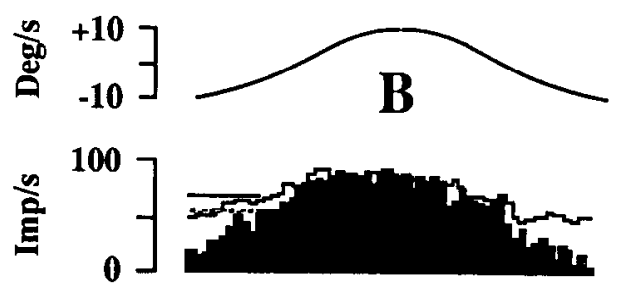

11845

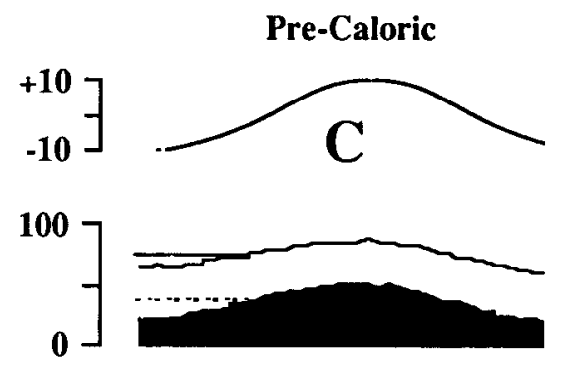

Post-Caloric

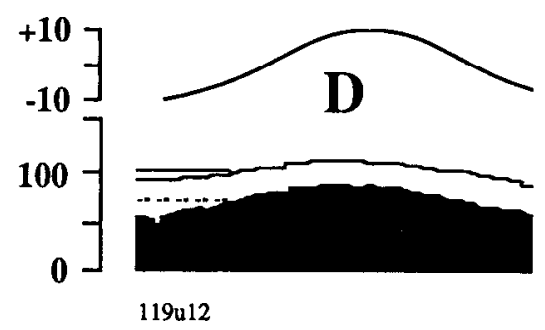

Figure 9. Comparison of caloric and efferent stimulation on the rotational responses of 2 high-gain afferents $(A, B$ and $C, D$ ). Responses are compared within and across the precaloric ( $A$ and $C)$ and postcaloric $(B$ and $D)$ conditions. Histograms arc in the samc format as Figure 5. For each afferent the responses were examined at $0.5 \mathrm{~Hz}$ $( \pm 10 \% \mathrm{sec})$. Scales of the histograms are the same in $A$ and $B$ but different in $C$ and $D$. 
A

Figure 10. Uncommon inhibitory responses of 2 canal afferents to electrical efferent stimulation. Upper panel in each set of records shows the afferent's background rate is decreased by efferent stimulation; downward and upward arrows indicate the onset and termination, respectively, of the electrical pulses applied to the brain stem. The lower panel in each set of records shows the responses in cycle histograms (same format as Fig. 5) to control rotations and to combined efferent stimulation; test stimuli were $0.5 \mathrm{~Hz}, \pm 10 \% / \mathrm{sec}$. For the high-gain afferent in $A$ and the acceleration afferent in $B$ electrical stimulation of central efferent neurons low. ered the DC firing rate and the peak rate, and decreased the sensitivity.
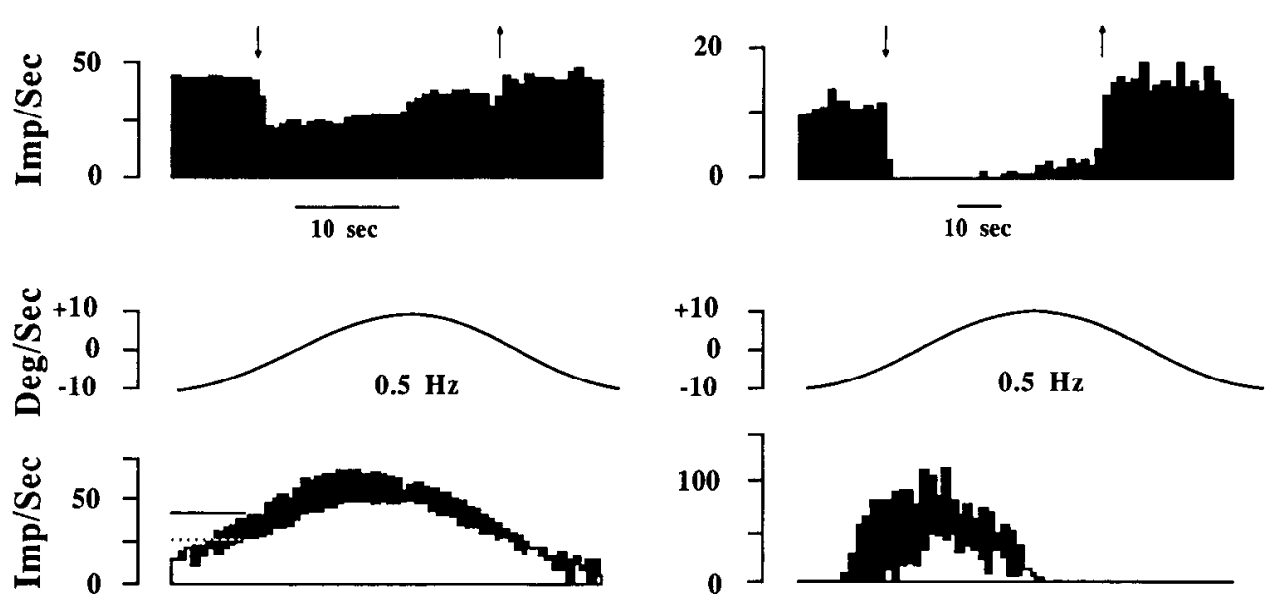

$136 u 1$
B
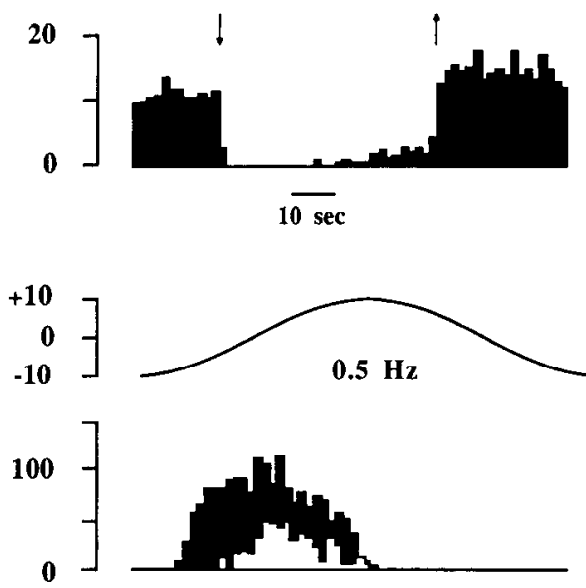

116u2 amount, but at these 2 rates the sensitivity decreases were the same. Thus in these afferents an unequivocal reduction in sensitivity independent of rate was produced by EVS stimulation. Also note in Figures 8 and 9 that the phase was unaffected by caloric or EVS stimuli.

\section{Inhibitory responses}

Of the 144 afferents studied during electrical EVS activation, 4 displayed atypical inhibitory responses to EVS stimulation. Two of these afferents are illustrated in Figure 10. The upper plots in $A$ and $B$ show the inhibitory effect of EVS stimulation on the afferent's background discharge, and the lower histograms show the afferent's response, both at $0.5 \mathrm{~Hz}( \pm 10 \% \mathrm{sec})$, during control cycles (blackened histograms) and during rotation with EVS stimulation (whitened histograms). In $A$, the background rate of this high-gain afferent was decreased from $43.0(\mathrm{CV}=0.08)$ to a low of $21.3 \mathrm{imp} / \mathrm{sec}(\mathrm{CV}=0.18$ at this rate) with EVS stimulation. During rotational testing, EVS stimulation lowered the average and DC firing rates from 40.8 to $25.5 \mathrm{imp} / \mathrm{sec}$, the peak rate from 66.8 to $44.7 \mathrm{imp} / \mathrm{sec}$, and the sensitivity from 2.6 to $1.7 \mathrm{imp} / \mathrm{sec}$ per $\% \mathrm{sec}$. One other high-gain afferent behaved in a similar manner (not shown). In $B$, the background discharge of an acceleration afferent was silenced during EVS stimulation. For this afferent and one other acceleration afferent, EVS stimulation reduced the DC firing rate, the peak rate, and the sensitivity. Thus, even though the EVS had inhibitory effects on the rate of these afferents, their sensitivity to rotation was also decreased in similarity to the majority of the population.

\section{Discussion}

It is noteworthy that the range of effective shock rates of electrical EVS stimulation overlaps the firing rates of central efferent neurons under quasinatural conditions $(80-100 \mathrm{imp} / \mathrm{sec}$; Highstein and Baker, 1985). Because efferent neurons are electrically coupled and appear uniform in their responses to a variety of stimuli, it may be suggested that electrical EVS stimulation activates this group of neurons in a fashion akin to their activation in intact behaving fish. When activated, the principal action of the EVS in toadfish is a rate increase in primary afferents. That this action is not an artifact of clcctrical stimulation is supported by the similar results obtained using a paradigm that behaviorally activates the system.

It is also surprising that electrical stimulation of the brain stem in the region of the EVS evokes a motor arousal apparently similar to that elicited in alert fish. The fish may have a limited behavioral repertoire that is initiated by a variety of stimuli, including central brain-stem stimulation, or this motor arousal may be specifically activated via the same neural circuitry utilized by the fish in a more natural setting.

The ultrastructure of the peripheral EVS includes efferenthair cell and efferent-primary afferent dendrite synapses (Nakajima and Wang, 1974; Sans and Highstein, 1984). The exact distribution of efferent synapses on hair cells and afferent dendrites across the sensory epithelium of the crista has not been established. In a morphophysiological study (Boyle and Highstein, 1986) individual afferents tested under similar conditions were intracellularly labeled with horseradish peroxidase and their dendritic terminations in the crista determined. Dendritic terminations of low-gain afferents were limited to the peripheral crista, low-firing-rate high-gain and acceleration afferents projected to the central regions of the crista, and the other highgain and acceleration afferents were found between. The response magnitude of the various afferents to EVS stimulation appears to follow a similar geometry, suggesting that either the synaptic efficacy of the efferents is regionally varied or the efferent projection to the crista is more dense centrally than peripherally.

The synaptic action of the EVS on afferents may be divided into 2 components: a rate increase and a gain reduction to adequate hair cell stimulation. Both actions are seen concurrently when the afferent's rotational response is examined. The majority of afferents studied (140/144, or $97.2 \%)$ showed a rate increase to EVS stimulation. An average rate (imp/sec over the cycle) was calculated to evaluate the response symmetry to rotation and to compare the rate increases in background and rotation-induced discharges to EVS stimulation. Compare the average rate for the rotational responses to the corresponding background rate for each afferent group in control and efferent conditions (see Table 1). These values are nearly identical, suggesting that EVS stimulation produces an equivalent rate in- 
crease while the animal is motionless and when the afferent is subjected to hair cell synaptic modulation produced by rotation. This comparison also indicates that an individual afferent has a certain, almost fixed rate that can be modulated by rotation. That is, adequate hair cell stimulation does not change the afferent's average rate, only contours it. EVS stimulation scales the rate to a higher level but the modulation remains centered about the new rate. For afferents having a full-cycle modulation, a difference in the background and DC firing rates (by definition half of peak-to-peak modulation) would indicate a greater or lesser response for one particular direction of rotation. This was not observed in our sample of afferents either for control cycles alone or for cycles combined with EVS stimulation. Thus the afferents show a response symmetry that remains preserved during EVS stimulation. In 4 cases $(4 / 144$, or $2.7 \%$ ) EVS stimulation reduced the afferents' rate both at rest and during rotation. In these few inhibited afferents also, the background rate and average rate during rotation within control and efferent conditions were the same.

Inhibitory responses have been described for the cat $(8 / 45$, or $8.9 \%$, while the remaining afferents were unaffected; Dieringer et al., 1977) and the squirrel monkey $(3 / 604$, or $0.5 \%$, while the remaining afferents were facilitated; Goldberg and Fernandez, 1980) and when present were observed only for afferents having low discharge rates. However, in the latter study many more afferents having low discharge rates were seen to be excited. The 4 afferents in our sample that were inhibited by EVS stimulation appear to be different from their mammalian counterparts: their mean background rate was $29.8 \mathrm{imp} / \mathrm{sec}$ (range 5.6-60.5) and therefore fell well within the range of that observed for most canal afferents (see Table 1, Background).

All afferents whose response sensitivities were affected by EVS stimulation-including the 4 afferents in which the background rate was also decreased, not increased-showed a sensitivity decrease. That this reduction was not due to a method error in estimating the sensitivity of afferents showing a discharge silencing or cut-off response was shown using caloric stimulation (Fig. 8, $A, B$ ).

It is generally accepted that caloric stimulation facilitates afferent discharge via a quasinatural mechanism involving increased transmitter release from hair cells that results in increased afferent depolarization. In low-rate afferents, the sensitivity to rotation may be influenced by a calorically induced rate increase (e.g., Fig. $8, A, C, D$; Fig. 9, $A, B$ ); however, this caloric effect was observed only after the rate had been elevated by a factor of 3 or more by successive stimuli. Whether the depolarization of hair cells opens voltage-sensitive channels that shunt receptor current causing proportionally less transmitter release for the same adequate stimulus or whether the same amount of transmitter is released in control and experimental trials but is less effective in its depolarizing action on afferents cannot be determined utilizing the present experimental approach. In contrast, EVS stimulation consistently reduced the sensitivity at all rate increases, even at those matching the caloric response, and in many afferents the sensitivity reduction was independent of the rate increase (e.g., Fig. 9, $C, D$ ). While the mechanism of efferent gain reduction has also not yet been elucidated, it is apparent that there is an efferent action in this regard in distinction to that evoked via calorization of the labyrinth.

It is noted that there are both postsynaptic terminals on afferents as well as presynaptic efferent terminals on hair cells.
There is also a dual, sometimes differential action of the EVS, i.e., the action upon rate and that upon gain to adequate stimulation. Whether one set of synapses may be controlling the afferent's output rate while the other may modulate the input gain cannot be directly tested using our paradigms.

Even in strongly affected afferents, EVS stimulation never completely demodulated the afferent's discharge to rotation. It is not known how much an afferent's response gain can be reduced before its specific reflex evoked by head movement deteriorates. In some high-gain and acceleration afferents, where EVS stimulation could lower the sensitivity by $93 \%$, the sensilivity was still on the average similar or higher than that of the low-gain afferents to control cycles alone. It must also be noted that the increased rate may prime the reflex pathway for activation. Thus, even though the gain is deceased, there may ultimately be more impulse traffic through the pathway than in conditions before EVS activation. These arguments should, however, be tempered by the realization that gain is a descriptive construct of input-output relations and may also be bound by simple metabolic constraints.

The major distortion component of the afferent's response to rotation is in the form of saturation or response clipping. Clipping may occur from a silencing of the discharge in the offdirection of rotation to a plateauing of the discharge that limits the peak rate in the on-direction of rotation. Presumably this latter form of nonlinearity occurs presynaptic to the afferent fiber, since raising the afferent's rate to higher levels, by using different rotational or efferent or caloric stimuli, does not in itself drive the afferent to an upper rate limit. When clipping occurs, information can be encoded as rate changes only by the rising and falling phases of the modulation, and the information over the remaining portions of the stimulus cycle is lost. Efferent activation may serve to improve the afferent's bidirectional response and reduce the amount of signal distortion by raising the discharge to a rate that effectively prevents the silencing. High-gain and acceleration afferents having low rates exhibit the largest responses to EVS stimulation and the greatest amounts of both forms of response distortion. Because of their remarkable sensitivity to rotation, these afferents are quickly silenced over increasing portions of the cycle as the frequency and amplitude are increased. Here EVS stimulation extends the time of discharge conduction to include the entire cycle, even for high-frequency and large-amplitude rotational stimuli (see Fig. 7). Prevention of the discharge silencing (low end saturation) may benefit the vestibular reflexes where motion in one direction is as equally important as motion in the opposite sense. In several cases EVS stimulation also minimized the upper distortion of response to rotations in the on-direction by producing a more sinusoidally modulated discharge; the data are, however, too subtle to be presently evaluated in depth.

Electrical EVS stimulation modified the afferents' rate but did not alter their specific input-output functions to angular head acceleration at any rotation test examined. This was found for low-gain afferents that may lag peak stimulus velocity by up to $20^{\circ}$ or more and for acceleration afferents that may lead peak stimulus velocity by more than $90^{\circ}$. In the previous paper (Boyle and Highstein, 1990) the transfer functions of the afferent's frequency response were characterized as low-pass and high-pass operations. The response of low-gain afferents was dominated by a first-order low-pass filter, high-gain afferents behaved as bandpass filters, and acceleration afferents were modeled to an accelerometer or a powerful lead operator that partially nulls 
the filtering of the lower frequencies of rotation. The time constants governing the filters remained unchanged and only a scaling factor to accommodate the sensitivity decrease was introduced by efferent stimulation.

\section{References}

Bell C (1981) Central distribution of octavolateral afferents and efferents in a teleost (mormyridae). J Comp Neurol 195:391-414.

Boyle R, Highstein SM (1985a) Effects of activation of the efferent vestibular system upon the response dynamics of the primary afferents of the horizontal semicircular canal in the toadfish, Opsanus tau. Biol Bull 169:547.

Boyle R, Highstein SM (1985b) Effects of behavioral activation of the efferent vestibular system on the response dynamics of the horizontal scmicircular canal afferents in the toadfish, Opsanus tau. Soc Neurosci Abstr 11:695.

Boyle R, Highstein SM (1986) Morphological correlates of physiological properties of horizontal semicircular canal afferents in the toadfish, Opsanus tau. Soc Neurosci Abstr 12:254.

Boyle R, Highstein SM (1990) Resting discharge and response dynamics of horizontal semicircular canal afferents of the toadfish, $O p$ sanus tau. J Neurosci 10:1557-1569.

Claas B, Munz H (1980) Bony fish lateral line efferent neurons identified by retrograde axonal transport of horseradish peroxidase (HRP). Brain Res 193:249-253.

Dieringer N, Blanks RHI, Precht W (1977) Cat efferent vestibular system: weak suppression of primary afferent activity. Neurosci Lett 5:285-290.

Flock A, Russcll IJ (1973) The post-synaptic action of efferent fibres in the lateral line organ of the burbot Lota lota. J Physiol (Lond) 235; 591-605.

Flock A, Russell I (1976) Inhibition by efferent nerve fibres: action on hair cells and afferent synaptic transmission in the lateral line canal organ of the burbot Lota lota. J Physiol (Lond) 257:45-62.

Gacek RR, Lyon M (1974) The localization of vestibular efferent neurons in the kitten with horseradish peroxidase. Acta Otolaryngol 77:92-101.

Gacek RR, Nomura Y, Balogh K (1965) Acetylcholinesterase activity in the efferent fibers of the stato-acoustic nerve. Acta Otolaryngol 59: 541-553.

Goldberg JM, Fernandez C (1980) Efferent vestibular system in the squirrel monkey: anatomical location and influence on afferent activity. J Ncurophysiol 43:986-1025.

Hartmann R, Klinke R (1980) Discharge properties of afferent fibres of the goldfish semicircular canal with high frequency stimulation. Pfluegers Arch 388:111-121.
Highstein SM, Baker R (1985) Action of the efferent vestibular system upon primary afferents in the toadfish, Opsanus tau. J Neurophysiol 54:370-384.

Highstein SM, Baker R (1986) Organization of the efferent vestibular nuclei in the toadfish, Opsanus Tau. J Comp Neurol 243:309-325.

Klinke R, Galley N (1974) Efferent innervation of vestibular and auditory receptors. Physiol Rev 54:316-357.

Lindeman HH (1970) Studies of the morphology of the sensory regions of the vestibular apparatus. Erg Anat 42:1-113.

Llinas R, Precht W (1969) The inhibitory vestibular efferent system and its relation to the cerebellum in the frog. Exp Brain Res 9:1629.

Meredith GE, Roberts BL (1986) Central organization of the efferent supply to the labyrinthine and lateral line receptors of the dogfish. Neuroscience 17:319-324.

Meredith GE, Roberts BL (1987) Distribution and morphological characteristics of efferent neurons innervating end organs in the ear and lateral line of the European eel. J Comp Neurol 265:494-506.

Nakajima Y, Wang DA (1974) Morphology of afferent and efferent synapses in hearing organ of the goldfish. J Comp Neurol 156:403416.

Rasmussen GL, Gacek RR (1958) Concerning the question of an efferent fiber component of the vestibular nerve of the cat. Anat Rec 130:361-362.

Rossi ML, Prigioni I, Valli P, Casella C (1980) Activation of the efferent system in the isolated frog labyrinth: effects on the afferent EPSPs and spike discharge recorded from single fibres of the posterior nerve. Brain Res 185:125-137.

Russell IJ (1971) The role of the lateral-line efferent system in Xenopus laevis. J Exp Biol 54:621-641.

Sala $O(1965)$ The efferent vestibular system. Electrophysiological research. Acta Otolaryngol Suppl 197:1-34.

Sans A, Highstein SM (1984) New ultrastructural features in the vestibular labyrinth of the toadfish, Opsanus tau. Brain Res 308:191195.

Schwarz IE, Schwarz DWF, Fredrickson JM, Landolt JP (1981) Efferent vestibular neurons: a study employing retrograde tracer methods in the pigeon (Columba livia). J Comp Neurol 196:1-12.

Smith CA, Rasmussen GL (1968) Nerve endings in the macula and crista of the chinchilla vestibule, with a special reference to the efferents. In: Third symposium on the role of the vestibular organs in space exploration, pp. 183-201. Washington, DC: NASA.

Warr BW, Guinan JJ (1979) Efferent innervation of the organ of Corti: two separate systems. Brain Res 173:152-155.

Wersall J (1956) Studies on the structure and innervation of the sensory epithelium of the cristae ampullaris in the guinea pig. A light and electron microscopic investigation. Acta Otolaryngol Suppl 126:185 . 